\title{
Quantitative Ratiometric pH Imaging Using a 1,2-Dioxetane Chemiluminescence Resonance Energy Transfer Sensor
}

Lucas S. Ryan, Jeni Gerberich, Uroob Haris, ralph mason, Alexander Lippert

Submitted date: 02/05/2020 - Posted date: 05/05/2020

Licence: CC BY-NC-ND 4.0

Citation information: Ryan, Lucas S.; Gerberich, Jeni; Haris, Uroob; mason, ralph; Lippert, Alexander (2020): Quantitative Ratiometric pH Imaging Using a 1,2-Dioxetane Chemiluminescence Resonance Energy Transfer Sensor. ChemRxiv. Preprint. https://doi.org/10.26434/chemrxiv.12235361.v1

Regulation of physiological $\mathrm{pH}$ is integral for proper whole-body and cellular function, and disruptions in $\mathrm{pH}$ homeostasis can be both a cause and effect of disease. In light of this, many methods have been developed to monitor $\mathrm{pH}$ in cells and animals. In this study, we report a chemiluminescence resonance energy transfer (CRET) probe Ratio-pHCL-1, comprised of an acrylamide 1,2-dioxetane chemiluminescent scaffold with an appended $\mathrm{pH}$-sensitive carbofluorescein fluorophore. The probe provides an accurate measurement of $\mathrm{pH}$ between 6.8-8.4, making it viable tool for measuring $\mathrm{pH}$ in biological systems. Further, its ratiometric output is independent of confounding variables. Quantification of $\mathrm{pH}$ can be accomplished both using common fluorimetry and advanced optical imaging methods. Using an IVIS Spectrum, $\mathrm{pH}$ can be quantified through tissue with Ratio-pHCL-1, which has been shown in vitro and precisely calibrated in sacrificed mouse models. Initial studies showed that intraperitoneal injections of Ratio-pHCL-1 into sacrificed mice produce a photon flux of more than $10^{\wedge} 10$ photons per second, and showed a significant difference in ratio of emission intensities between $\mathrm{pH} 6.0,7.0$, and 8.0.

File list (2)

LRyan et al ChemRxiv Ratio-pHCL-1 Manuscript.pdf (869.89 KiB)

view on ChemRxiv - download file

LRyan et al ChemRiv Ratio-pHCL-1 SI.pdf (2.67 MiB)

view on ChemRxiv - download file 


\title{
Quantitative ratiometric pH imaging using a 1,2-dioxetane chemilu- minescence resonance energy transfer sensor
}

\author{
Lucas S. Ryan, ${ }^{\dagger}$ Jeni Gerberich, ${ }^{\#}$ Uroob Haris, ${ }^{\dagger}$ Ralph P. Mason, ${ }^{\#}$ and Alexander R. Lippert*,†, ,, \\ †Department of Chemistry, ${ }^{\S}$ Center for Drug Discovery, Design, and Delivery (CD4), and ${ }^{\llbracket}$ Center for Global Health Impact \\ (CGHI), Southern Methodist University, Dallas, TX 75275-0314. *E-mail: alippert@ smu.edu. Fax: 214-768-4089.
}

\#Prognostic Imaging Research Laboratory (PIRL), Pre-clinical Imaging Section, Department of Radiology, UT Southwestern Medical Center, Dallas, TX 75390-9058, USA.

\begin{abstract}
Regulation of physiological $\mathrm{pH}$ is integral for proper whole-body and cellular function, and disruptions in $\mathrm{pH}$ homeostasis can be both a cause and effect of disease. In light of this, many methods have been developed to monitor $\mathrm{pH}$ in cells and animals. In this study, we report a chemiluminescence resonance energy transfer (CRET) probe Ratio-pHCL-1, comprised of an acrylamide 1,2-dioxetane chemiluminescent scaffold with an appended $\mathrm{pH}$-sensitive carbofluorescein fluorophore. The probe provides an accurate measurement of $\mathrm{pH}$ between 6.8-8.4, making it viable tool for measuring $\mathrm{pH}$ in biological systems. Further, its ratiometric output is independent of confounding variables. Quantification of $\mathrm{pH}$ can be accomplished both using common fluorimetry and advanced optical imaging methods. Using an IVIS Spectrum, pH can be quantified through tissue with Ratio-pHCL-1, which has been shown in vitro and precisely calibrated in sacrificed mouse models. Initial studies showed that intraperitoneal injections of Ratio-pHCL-1 into sacrificed mice produce a photon flux of more than $10^{10}$ photons per second, and showed a significant difference in ratio of emission intensities between $\mathrm{pH}$ 6.0, 7.0, and 8.0.
\end{abstract}

\section{Introduction}

Regulation of physiological $\mathrm{pH}$ is an important factor for maintaining homeostasis. Whole body $\mathrm{pH}$ is regulated through numerous methods, including renal control of bicarbonate storage, ${ }^{1}$ ammonia excretion, ${ }^{2,3} \mathrm{CO}_{2}$ respiration ${ }^{4}$, and excretion of non-volatile acids obtained from the diet. ${ }^{3}$ These processes are controlled at a subcellular level through active transport by $\mathrm{H}^{+}-$ ATPase, and passive transport by $\mathrm{Na}^{+} / \mathrm{HCO}_{3}{ }^{-}$coporters, ${ }^{5,6}$ and $\mathrm{Cl}^{-} / \mathrm{HCO}_{3}{ }^{-}$and $\mathrm{Na}^{+} / \mathrm{H}^{+}$antiporters. ${ }^{7}$ Deviations in $\mathrm{pH}$ homeostasis can have major implications on cellular and whole body function and can be both a cause and effect of disease states. For example, untreated type 1 diabetes can result in ketoacidosis (a lowering of blood $\mathrm{pH}$ from overproduction of ketone bodies in $\beta$-oxidation of fatty acids) due to insulin deficiency. ${ }^{8}$ Diseases associated with chronic inflammation display decreased $\mathrm{pH}$ levels, and are positively correlated with increased cancer risk. ${ }^{9}$ Extracellular $\mathrm{pH}$ is also altered in malignant tumors, as cancer cells generate excess lactate due to increased rates of glycolysis, even in the presence of sufficient $\mathrm{O}_{2}$ needed for aerobic oxidation. ${ }^{10}$ Because of their highly heterogenous microenvironments, tumors often display "hot spots" of increased acidity. ${ }^{11}$ The ability to accurately quantify $\mathrm{pH}$ in a pre-clinical and clinical setting is critical to understand its impact on human health.

Current clinical methods to detect $\mathrm{pH}$ in living systems include magnetic resonance imaging (MRI) techniques such as intra and extracellular ${ }^{31} \mathrm{P}$ MRI, ${ }^{12}$ chemical exchange saturation transfer (CEST) MRI, ${ }^{13-15}$ and other infused reporter molecules, notably ${ }^{19}$ F-based agents, which can provide a large chemical shift range, but often suffer from poor signal to noise. ${ }^{16}$ These methods, however, can be time consuming and often require extensive training and expertise. Preclinical techniques for $\mathrm{pH}$ detection offer a more cost-effective approach to study $\mathrm{pH}$ a laboratory setting. Insertion of $\mathrm{pH}$ microelectrodes have been used for preclinical measurement of $\mathrm{pH}$ in tumors, ${ }^{17,18}$ but is invasive and may disturb tumor physiology. Optical imaging using luminescent $\mathrm{pH}$ reporters has been extensively developed in recent years, ${ }^{19-23}$ however, these compounds can be challenging to apply in vivo due to changes in luminescence intensity through tissue, hampering the ability to acquire accurate measurements. Ratiometric imaging agents circumvent this issue by providing an internal reference, and this technology has been utilized in GFP, ${ }^{24}$ luciferase, ${ }^{25}$ quantum dot, ${ }^{26,27}$ and nanoparticle-based $^{28-30}$ agents for $\mathrm{pH}$. However, no small molecule ratiometric chemiluminescence agents have been made for in vivo application.

Chemiluminescence is light generation through an exothermic chemical reaction, and is achieved through the breaking of chemical bonds. Specifically, 1,2-dioxetane compounds have garnered interest in this area due to their innate ability for triggered chemiluminescence emission via chemically initiated electron exchange luminescence (CIEEL). ${ }^{31,32}$ This technology has been employed for imaging analytes by protecting the chemiluminophore with an analyte selective trigger ${ }^{33}$ Upon deprotection of the dioxetane by the analyte, it will undergo CIEEL and luminesce. This strategy has been employed for detection of various analytes including hypoxia, ${ }^{34-36}$ hydrogen sulfide, ${ }^{37}$ peroxynitrite, ${ }^{38}$ nitroxyl, ${ }^{39}$ cathepsin $\mathrm{B},{ }^{40} \beta$-galactosidase, ${ }^{41,42}$ formaldehyde, ${ }^{43}$ and others ${ }^{4-52}$ Chemiluminescence provides many advantages compared to other optical methods in vivo by providing its own light source, thus attenuating autofluorescence and light scattering effects. ${ }^{53}$ Chemiluminescent probes have also been shown to achieve much higher fold turnon than comparable fluorophores. ${ }^{39}$ Furthermore, they do not 


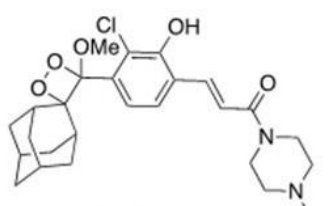

Ratio-pHCL-1

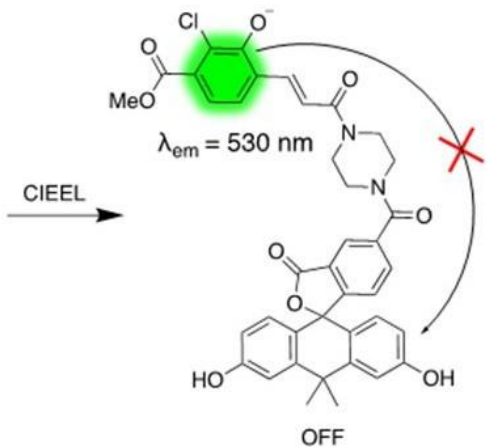

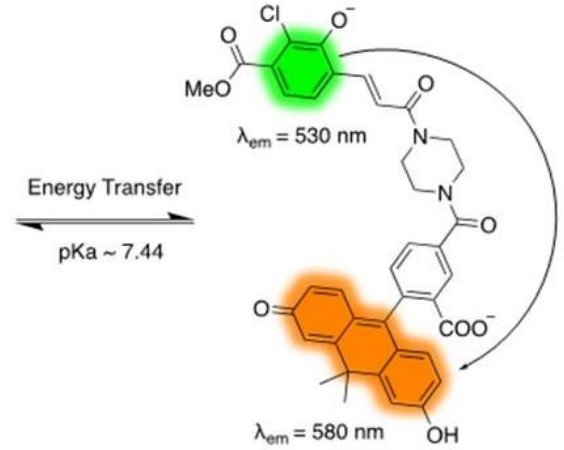

require expression of an enzyme for use, making them valuable standalone optical imaging tools as opposed to bioluminescence methods for monitoring $\mathrm{pH} .^{25}$

A major driver for both chemiluminescence and fluorescence in vivo imaging is the development of luminophores with high quantum yields and redshifted emission. Fluorophore development has flourished in this area, particularly with modifications to BODIPY, ${ }^{54-57}$ xanthene, ${ }^{58-63}$ and cyanine ${ }^{64-66}$ cores. However, red-shifting emission of 1,2-dioxetane chemiluminescent compounds has been difficult. Arguably the largest breakthrough in this area in recent years was the development of acryl-substituted phenoxy dioxetanes that greatly increased quantum yield and shifted emission to near $530 \mathrm{~nm} .{ }^{67} \mathrm{NIR}$ chemiluminescent scaffolds have also been reported, but are less emissive. ${ }^{68}$ One strategy to obtain bathochromic emission is by pairing donor and acceptor luminophores through resonance energy transfer mechanisms. Fluorescence resonance energy transfer (FRET) pairs have been rigorously vetted, and are often used to detect macromolecular interactions in biochemical applications. ${ }^{69}$ FRET also allows for fluorophores to be paired to dyes with sensing capabilities, thus providing ratiometric detection of analytes with the FRET pair. ${ }^{70-73}$ It is currently known that 1,2-dioxetanes exhibit energy transfer capabilities, ${ }^{74-76}$ but to our knowledge, no single-molecule ratiometric chemiluminescent probes for imaging $\mathrm{pH}$ have been developed. Here, we report the first single molecule ratiometric chemiluminescence resonance energy transfer (CRET) sensor quantifying $\mathrm{pH}$ in living systems (Scheme 1).

\section{Experimental Procedure}

In vitro calibration of Ratio-pHCL-1. Chemiluminescent emission spectra were acquired using a Hitachi F-7000 fluorescence spectrophotometer via the luminescence detection module and scanning luminescence emission from 400-900 nm in response to exposure of Ratio-pHCL-1 to pH buffered solutions. A solution of $20 \mu \mathrm{M}$ Ratio-pHCL-1 in DMSO was added to a solution of $100 \mathrm{mM}$ Tris, PBS or carbonate buffers ranging from $\mathrm{pH}$ 6.81-8.42. For concentration dependence, 10, 20, and $40 \mu \mathrm{M}$ Ratio-pHCL-1 in 5\% DMSO were subjected to $100 \mathrm{mM}$ PBS buffered to $\mathrm{pH} 6.81$, 7.45, and 8.02. For time dependence, $20 \mu \mathrm{M}$ Ratio-pHCL-1 in 5\% DMSO was subjected to $100 \mathrm{mM}$ PBS buffered to $\mathrm{pH}$ $6.81,7.45$, and 8.02, and the chemiluminescence emission spectra was measured at $t=0,10,20$ and $30 \mathrm{~min}$. For DMSO dependence, $20 \mu \mathrm{M}$ Ratio-pHCL-1 in a final concentration of 1,5 , or $10 \%$ DMSO was subjected to $100 \mathrm{mM}$ PBS buffered to $\mathrm{pH} 6.81,7.45$, or 8.02 . Each experiment was independently conducted 3 times, and analysis of each experiment was conducted by dividing emission intensity values at $580 \mathrm{~nm}$ by emission intensity values at $530 \mathrm{~nm}$ from the emission plot.

Ratio-pHCL-1 kinetics. Kinetics data were acquired using a Biotek Cytation $5^{\circledR}$ plate reader using the luminescence detection mode, end point read type. The temperature was set at $37^{\circ} \mathrm{C}$ under ambient atmosphere. The gain was set at 135 and the read height was set at $4.5 \mathrm{~mm}$. In a 96 -well plate, $1.0 \mu \mathrm{L}$ of $0.25 \mathrm{mM}$ Ratio-pHCL-1 was added to wells containing a solution of $237.5 \mu \mathrm{L} 100 \mathrm{mM}$ PBS (pH = 7.45) and $11.5 \mu \mathrm{L}$ DMSO to create a final concentration of $1.0 \mu \mathrm{M}$ Ratio-pHCL-1, 5\% DMSO. The plate was then immediately placed into the plate reader and allowed to stir for $1 \mathrm{~min}$. Luminescence readings were acquired every 2 min for 50 $\min$.

Ratiometric pH imaging. Chemiluminescence images were acquired with an IVIS Spectrum (Perkin Elmer, Waltham, MA) using the "Luminescent" and "Photograph" mode. For in vitro 96 well plate measurements, the exposure time was set as 0.5 seconds, binning was set to medium, F/stop was set as 4 , FOV was set as $\mathrm{C}(12.9 \mathrm{~cm})$, Excitation was blocked and the sequence was set for the emission mode, and images were acquired sequentially first using a $580 \mathrm{~nm}$ bandpass filter, then a $540 \mathrm{~nm}$ bandpass filter. A final concentration of $1 \mu \mathrm{M}$ RatiopHCL-1 was added to $100 \mathrm{mM}$ buffer ranging from $\mathrm{pH}$ 6.81-8.42. All images were analyzed using Living Image software. Image analysis was carried out by setting individual ROI's to each well for both 580 and $540 \mathrm{~nm}$ filter images. The ROI's were then measured, which gave a total flux $(\mathrm{p} / \mathrm{s})$ for each ROI, the flux value at $580 \mathrm{~nm}$ was divided by the flux at $540 \mathrm{~nm}$ for each well. For sacrificed mouse imaging, $950 \mu \mathrm{L}$ of 1.0 M PBS (pH 5.99-7.99) was injected into the peritoneal cavity of recently sacrificed CL6B57 mice aged 6-12 weeks old, then $50 \mu \mathrm{L}$ of $400 \mu \mathrm{M}$ Ratio-pHCL-1 in DMSO was injected shortly after to achieve an approximate final concentration of $20 \mu$ M Ratio-pHCL-1 with 5\% DMSO. The mice were imaged immediately after injection of Ratio-pHCL-1 with a $580 \mathrm{~nm}$ and $540 \mathrm{~nm}$ filter with capture settings set to autoexposure and FOV set to $\mathrm{C}(12.9 \mathrm{~cm})$. 
Scheme 2. Synthesis of Ratio-pHCL-1
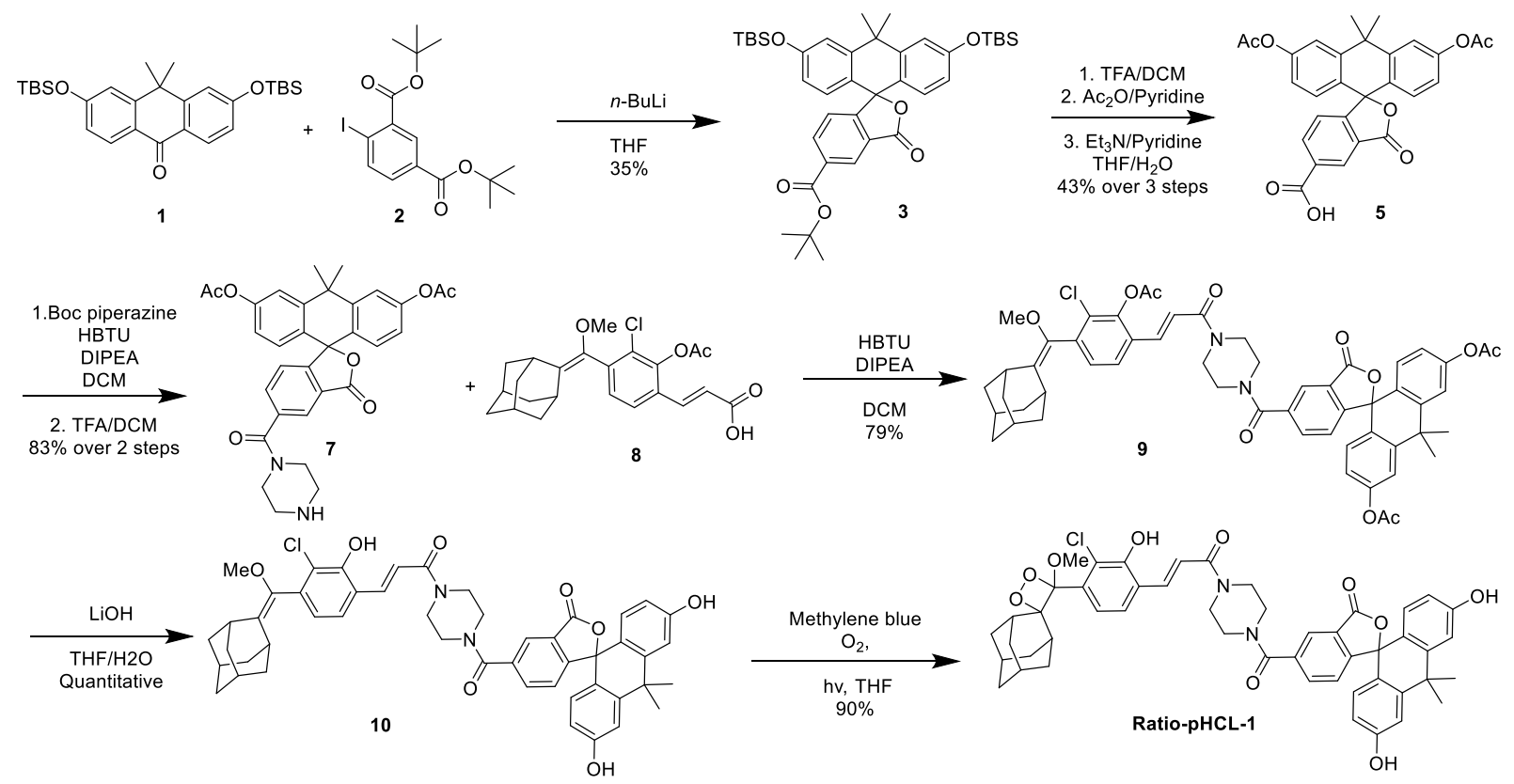

\section{Results}

In previous work, we have demonstrated ratiometric quantification of $\mathrm{pH}$ using the light emission from 1,2-dioxetane chemiluminophores. ${ }^{76}$ These studies, however, required the addition of the $\mathrm{pH}$ sensitive dye seminaptharhodafluor (SNARF) coupled with the addition of a chemiluminescence enhancer solution and were not viable for in vivo application. We sought a molecule with increased chemiluminescence quantum yields, red-shifted emission, and a $\mathrm{pH}$ sensitive fluorophore directly conjugated to the dioxetane scaffold for increased energy transfer efficiency and ease of use. Inspired by previously reported $\mathrm{pH}$-sensitive carbofluoresceins with fluorescent emissions near $580 \mathrm{~nm},{ }^{58}$ we postulated that conjugation of this fluorophore to the dioxetane scaffold could provide a ratiometric measure of $\mathrm{pH}$ (Scheme 1).

Synthesis of Ratio-pHCL-1 began with the with synthesis of tert-butyl-dimethylsilyl ether (TBS)-protected anthrone $\mathbf{1}$ from reported literature procedures (Scheme 2).$^{58}$ Due to difficulties in conjugation of the top segment of the fluorophore to $\mathbf{1}$ using reported Grignard metathesis to form the carbofluorescein unit, we decided to explore alternative methods. It has been shown that iodo compounds react faster than their bromo counterparts during lithium halogen exchange, ${ }^{77}$ so we proceeded to synthesize 2-iodo-tert-butyl-isophthalate (compound 2) from commercially available 2-aminoisophthalic acid. ${ }^{78}$ TBS-protected carbofluorescein 3 was successfully formed in 35\% yield by premixing $\mathbf{1}$ and $\mathbf{2}$, purging the mixture three times under vacuum, addition of dry THF, then addition of 1 equiv of $n-\mathrm{BuLi}$ at $0{ }^{\circ} \mathrm{C}$. This protocol proved to be general, and could be used for preparing other xanthene scaffolds, including silicon rhodamines (Scheme S1). We postulate that the faster rate of lithiumiodine exchange compared to nucleophilic addition of $n-\mathrm{BuLi}$ to the anthrone enables the use of $n$-BuLi as a safer alternative to tert-BuLi.

Compound $\mathbf{3}$ was further modified in order to conjugate it to the chemiluminescent scaffold. We simultaneously deprotected both the TBS and tert-butyl ester protecting groups with

trifluoroacetic acid (TFA). The xanthene phenols were protected with acetic anhydride to obtain $\mathbf{5}$, but it was noticed that a less polar spot as shown by thin layer chromatography (TLC) also formed during the reaction, which was presumed to be the mixed anhydride product. This spot disappeared by subjecting the crude mixture to one equivalent of $\mathrm{Et}_{3} \mathrm{~N}$ and five equivalents of pyridine in a $1: 1 \mathrm{THF} / \mathrm{H}_{2} \mathrm{O}$ mixture to produce 5 in a $64 \%$ yield. We then appended tert-butyl piperazine-1-carboxylate to 5 and subsequently deprotected the tert-butyloxy carbamate with TFA to obtain amine 7 .

The final steps were to conjugate the chemiluminescent scaffold and carbofluorescein together, deprotect to form the free phenol precursor, and form the dioxetane compound. We decided to also use an acetate protection strategy to form compound $\mathbf{8}$ from literature reported compound S7 in 64\% yield (Scheme S1). This was advantageous to preparation of the final probe because all three acetates could be deprotected in a single step. We proceeded to conjugate 7 and 8 together via 2-(1H-benzotriazol-1yl)-1,1,3,3-tetramethyluronium hexafluorophosphate (HBTU) coupling to form triacetate $\mathbf{9}$, which was subsequently deprotected with $1 \mathrm{M} \mathrm{LiOH}$ to form precursor $\mathbf{1 0}$ in quantitative yield. 10 underwent a light mediated [2+2] cycloaddition with singlet oxygen generated with methylene blue as a photosensitizer to obtain Ratio-pHCL-1 in $90 \%$ yield.

Upon synthesis of Ratio-pHCL-1, we proceeded to characterize its properties in vitro. We measured the chemiluminescence emission of $20 \mu$ M Ratio-pHCL-1 (100 mM PBS or TRIS, pH 6.81-8.42, 5\% DMSO). Analysis of the emission spectra over this $\mathrm{pH}$ range revealed one peak centered at $580 \mathrm{~nm}$ attributed to luminescence from the carbofluorescein scaffold, and a shoulder around $530 \mathrm{~nm}$ corresponding to CIEEL from the chemiluminescent scaffold (Figure 1A). As the $\mathrm{pH}$ of the system is increased, emission at both peaks increases due to increased concentration of phenolate over phenol, however, luminescence intensity from the carbofluorescein increases in this system to a greater extent than the luminescence from the chemiluminophore; analysis shows a 24 -fold change in the ratio of 

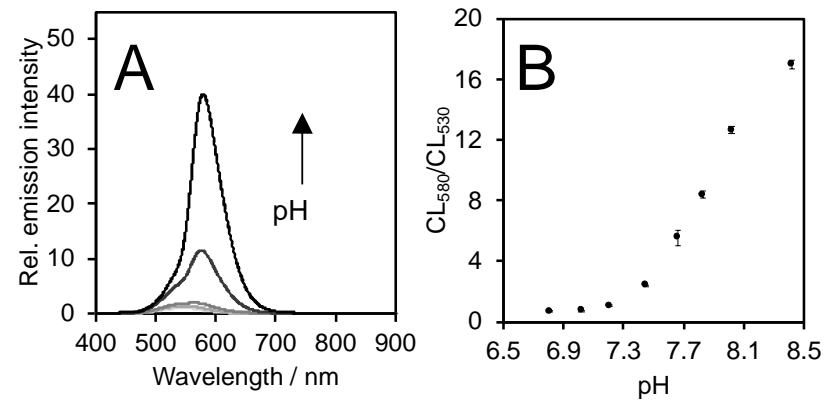

Figure 1. The $\mathrm{pH}$ dependent $(\mathrm{A})$ chemiluminescence emission spectra of $20 \mu \mathrm{M}$ Ratio-pHCL-1 and 5\% DMSO in $100 \mathrm{mM}$ PBS buffer from pH 6.81-7.63 and (B) ratio of chemiluminescence emission intensities at $580 \mathrm{~nm}$ and $530 \mathrm{~nm}$ of $20 \mu \mathrm{M}$ Ratio-pHCL-1 and 5\% DMSO in aqueous buffer $(\mathrm{pH}=6.81-$ 8.44). All measurements were taken in $100 \mathrm{mM}$ PBS or $100 \mathrm{mM}$ Tris, and measurements were taken $20 \mathrm{~s}$ after mixing. Error bars are \pm SD from $n=3$ independent experiments.
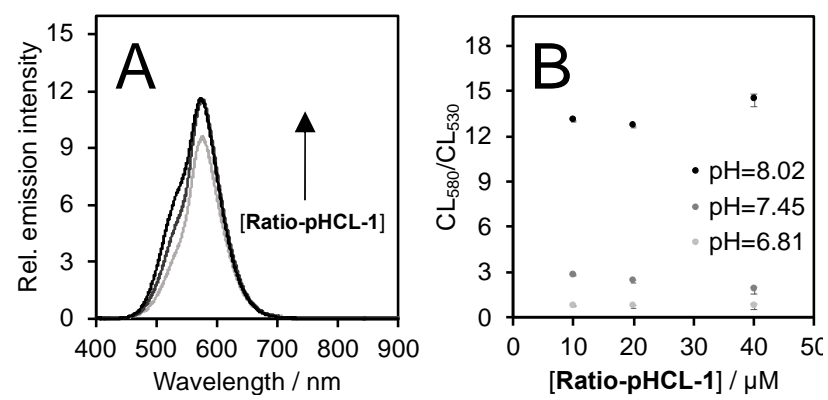

Figure 2. The dependence of chemiluminescence emission on the concentration of Ratio-pHCL-1. (A) Emission spectra at $\mathrm{pH}$ 7.45 and (B) ratio of the chemiluminescence emission intensity at $580 \mathrm{~nm}$ and $530 \mathrm{~nm}$ of 10,20 , and $40 \mu$ M Ratio-pHCL-1 in PBS buffer at $\mathrm{pH} 6.81$ (white trace), 7.45 (gray trace), and 8.02 (black trace) containing 5\% DMSO. All measurements were taken $20 \mathrm{~s}$ after mixing. Error bars are \pm SD from $n=3$ independent experiments.

emission intensities at $580 \mathrm{~nm}$ over $530 \mathrm{~nm}$ from $\mathrm{pH} 6.81-8.42$ (Figure 1B), demonstrating that the emission spectra of the Ratio-pHCL-1 is pH dependent. We then measured decomposition kinetics of $1.0 \mu \mathrm{M}$ Ratio-pHCL-1 (100 mM PBS, pH 7.45, $5 \%$ DMSO, $37^{\circ} \mathrm{C}$ ). Figure S2 shows an observed peak emission at the initial time point followed by a steady decline to baseline values over 50 minutes.

We subjected Ratio-pHCL-1 to variables to confirm its ratiometric response is independent of testing conditions. We first examined changes in emission spectra as compared with concentration of Ratio-pHCL-1 (Figure 2). We tested 10, 20, and $40 \mu$ Matio-pHCL-1 (100 mM PBS, pH 6.81-8.02, 5\% DMSO). Ratio-pHCL-1 shows a dose dependent increase in emission intensity as concentration increases, however, both peaks increase proportionally (Figure 2A). Analysis of the ratio of emission intensities at $580 \mathrm{~nm}$ and $530 \mathrm{~nm}$ plotted versus the concentration of Ratio-pHCL-1 reveals that the signal remains relatively consistent despite changes in its concentration (Figure 2B), only showing a slight downward trend with increasing concentration at $\mathrm{pH} 7.45$. We then subjected $20 \mu \mathrm{M}$ RatiopHCL-1 to varying DMSO concentrations (100 mM PBS, pH 6.81-8.02, 1-10\% DMSO). Ratio-pHCL-1 showed a dose dependent increase in overall emission intensity with increasing DMSO concentration, likely due to increases in
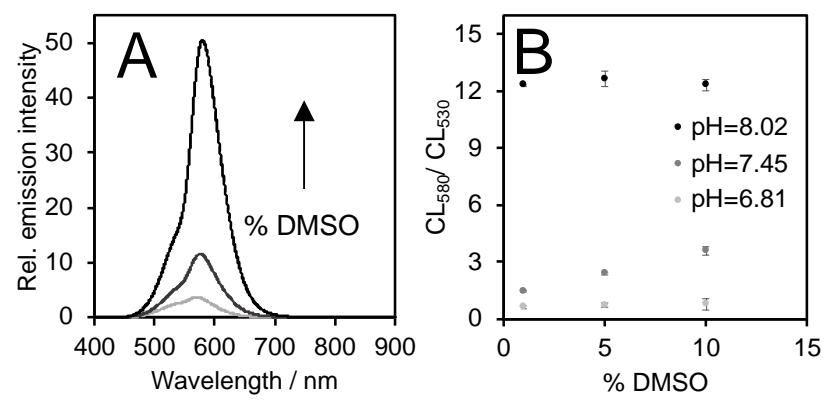

Figure 3. The dependence of chemiluminescence emission on the concentration of DMSO. (A) Emission spectra at $\mathrm{pH} 7.45$ with 1,5 , or $10 \%$ DMSO and (B) ratio of the chemiluminescence emission intensity at $580 \mathrm{~nm}$ and $530 \mathrm{~nm}$ of $20 \mu \mathrm{M}$ RatiopHCL-1 in PBS buffer at pH 6.81 (white trace), 7.45 (gray trace), and 8.02 (black trace) containing 1,5 or $10 \%$ DMSO. All measurements were taken $20 \mathrm{~s}$ after mixing. Error bars are \pm SD from $n=3$ independent experiments.
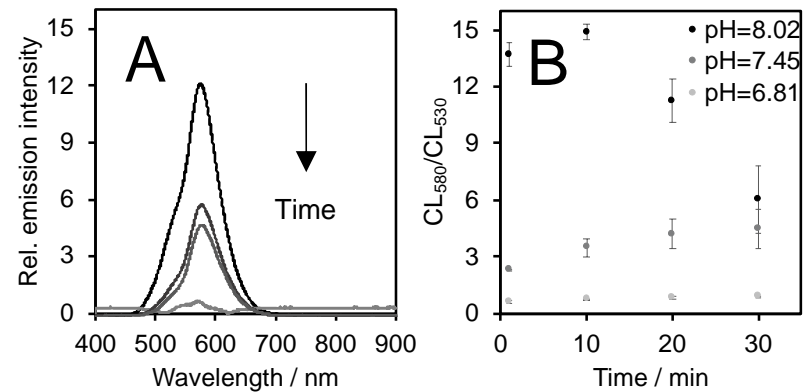

Figure 4. Time dependent (A) emission spectrum at $\mathrm{pH} 7.45$ and (B) ratio of the chemiluminescence emission intensities at $580 \mathrm{~nm}$ and $530 \mathrm{~nm}$ of $20 \mu$ M Ratio-pHCL-1 in $100 \mathrm{mM}$ PBS at pH 6.81 (white trace), 7.45 (gray trace), and 8.02 (black trace) containing 5\% DMSO. All measurements were taken $20 \mathrm{~s}$ after mixing. Error bars are \pm SD from $n=3$ independent experiments.

chemiluminescence quantum yield (Figure 3A). However, changes in DMSO concentration did not greatly change the ratio of emission intensities at 580 and $530 \mathrm{~nm}$, albeit showing a slight upward trend in chemiluminescence emission at $\mathrm{pH} 7.45$ (Figure 3B).

We then measured $20 \mu \mathrm{M}$ Ratio-pHCL-1 (100 mM PBS, pH 6.81-8.02) from $0-30 \mathrm{~min}$ with $10 \mathrm{~min}$ intervals to test probe stability over time. Figure $4 \mathrm{~A}$ reveals that the overall chemiluminescence intensity decreases over time, as was expected from free phenol dioxetane kinetics. Plotting the ratio of emission intensities at $580 \mathrm{~nm}$ over $530 \mathrm{~nm}$ does reveal changes in emission intensities over time, with a slight upward trend at $\mathrm{pH} 7.45$ and a more pronounced downward trend at $\mathrm{pH} 8.02$ over a 30 minute period (Figure 4B), likely due to more rapid decomposition kinetics at this $\mathrm{pH}$. These variations indicate that care should be taken when using Ratio-pHCL-1 at higher $\mathrm{pH}$ values. Imaging experiments should be performed quickly after injection to ensure equal comparisons, especially when measuring higher $\mathrm{pH}$ values. Next, we examined the behavior of RatiopHCL-1 in biological systems. Cellular uptake of $20 \mu \mathrm{M}$ Ratio-pHCL-1 in A549 cells was examined over an 80 min period (Figure S3), and changes in fluorescence were monitored using an EVOS fluorescence microscope. After washing the cells, increased intracellular fluorescence could be seen from the acrylamide and carbofluorescein motifs. These results show 
pH 6.87 .07 .27 .47 .77 .88 .08 .4
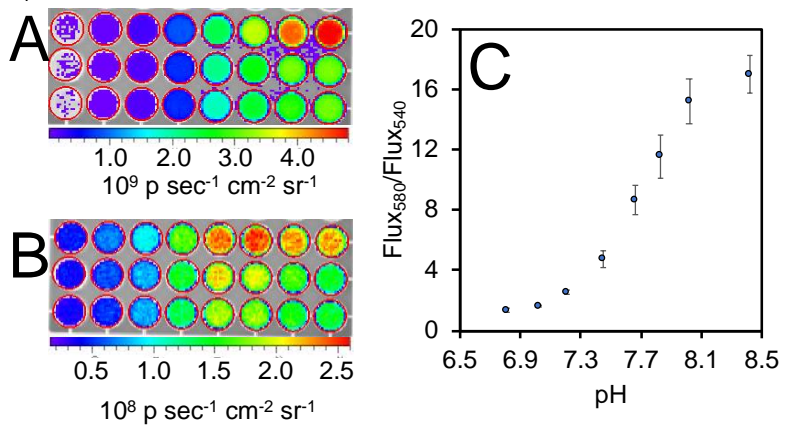

Figure 5. Chemiluminescence intensity images of the $\mathrm{pH}$ dependent emission of $1 \mu \mathrm{M}$ Ratio-pHCL-1 in $100 \mathrm{mM}$ PBS or Tris ( $\mathrm{pH}$ 6.81-8.42) containing 5\% DMSO using (A) $580 \mathrm{~nm}$ bandpass filter or (B) $540 \mathrm{~nm}$ bandpass filter in an IVIS Spectrum. (C) Ratio of total flux (p/s) at $580 \mathrm{~nm}$ and $540 \mathrm{~nm} . \mathrm{n}=12$ technical replicates across 4 independent experiments, error bars are \pm SD.
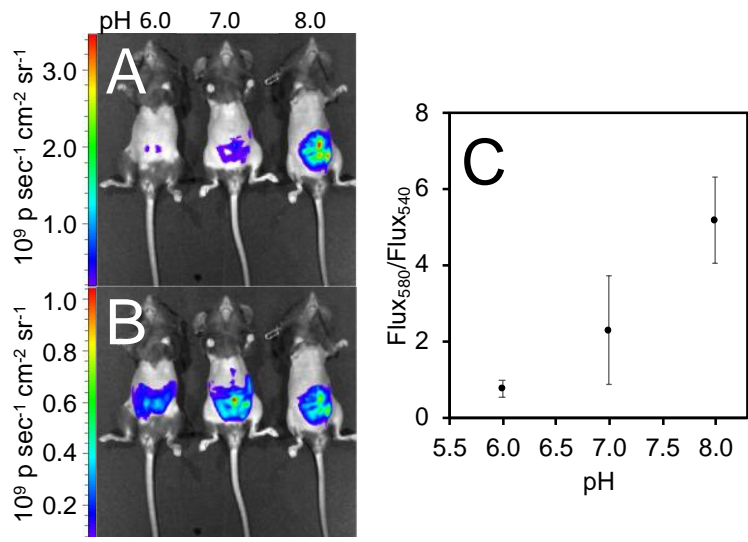

Figure 6. Chemiluminescence images of the $\mathrm{pH}$ dependent emission of $20 \mu \mathrm{M}$ Ratio-pHCL-1 in $1.0 \mathrm{M}$ PBS (pH 5.99-7.99) containing 5\% DMSO injected into the peritoneal cavity of sacrificed C57BL6 mice using a (A) $580 \mathrm{~nm}$ bandpass filter or (B) $540 \mathrm{~nm}$ bandpass filter in an IVIS Spectrum. (C) Ratio of total flux (p/s) at $580 \mathrm{~nm}$ and $540 \mathrm{~nm} . \mathrm{n}=3$ biological replicates for each $\mathrm{pH}$ tested, error bars are $\pm \mathrm{SD}$.

that Ratio-pHCL-1 can cross the cellular membrane and accumulate inside cells.

Upon completion of the in vitro spectrophotometry experiments and cellular studies, we confirmed the feasibility of quantitative pH imaging using Ratio-pHCL-1 in an IVIS Spectrum. We subjected Ratio-pHCL-1 to buffered solutions (100 mM PBS, $\mathrm{pH}$ 6.81-8.42, 5\% DMSO) and took sequential images using 580 and $540 \mathrm{~nm}$ bandpass filters and 0.5 second exposure time. Four independent experiments were completed, and each buffered solution was measured with three technical replicates per experiment. A solution of $20 \mu \mathrm{M}$ Ratio-pHCL-1 was too bright and saturated the images at this setting, so the concentration was lowered to $1.0 \mu \mathrm{M}$. Images of the plate taken with average radiance heat maps set to $10^{9}$ photons $\mathrm{sec}^{-1} \mathrm{~cm}^{-2} \mathrm{sr}^{-1}$ and $10^{8}$ photons $\mathrm{sec}^{-1} \mathrm{~cm}^{-2} \mathrm{sr}^{-1}$ for the $540 \mathrm{~nm}$ filter (Figure 5A, 5B, respectively) show that average radiance increases with $\mathrm{pH}$ on both filter settings. Plotting the flux (photons /s) at $580 \mathrm{~nm}$ over flux at $540 \mathrm{~nm}$ for each well shows an increase in the ratio between the two wavelengths over increase in $\mathrm{pH}$, and the generated curve trends well with our previous in vitro calibration. We then confirmed that a ratiometric chemiluminescence response could be measured through a tissue surrogate by placing a $2.8 \mathrm{~mm}$ thick slice of bologna (Kroger, Dallas, TX) atop a 96 well plate loaded with $20 \mu \mathrm{M}$ Ratio-pHCL-1 in buffered solutions (100 mM PBS or Tris, $\mathrm{pH} 6.81-8.42,5 \%$ DMSO) and took sequential $580 \mathrm{~nm}$ and $540 \mathrm{~nm}$ filtered images with 10.0 second exposure times (Figure S4), which clearly showed penetration through this tissue surrogate.

Finally, we investigated the response of Ratio-pHCL-1 in animal models. Recently sacrificed C57BL6 mice were given 950 $\mu \mathrm{L}$ intraperitoneal (IP) injections of 1.0 M PBS (pH 5.99-7.99), then subsequently given $50 \mu \mathrm{L}$ IP injections of $400 \mu \mathrm{M}$ RatiopHCL-1 to achieve a theoretical final concentration of $20 \mu \mathrm{M}$ Ratio-pHCL-1 with 5\% DMSO in the injection volume, and imaged with a $580 \mathrm{~nm}$ and $540 \mathrm{~nm}$ filter. With radiance heat maps of both 580 and $540 \mathrm{~nm}$ images set to $10^{9} \mathrm{p} \mathrm{sec}^{-1} \mathrm{~cm}^{-2} \mathrm{sr}^{-1}$ (Figure 6A, 6B) there is a clear increase in flux from the 580 nm image from $\mathrm{pH}$ 6.0-8.0, with a less pronounced increase in the $540 \mathrm{~nm}$ image over the same $\mathrm{pH}$ range. Plotting total flux at $580 \mathrm{~nm}$ over flux at $540 \mathrm{~nm}$ shows an increase in the ratio of total flux from both filter sets with increasing $\mathrm{pH}$ (Figure 6C), demonstrating that Ratio-pHCL-1 can discern changes in $\mathrm{pH}$ in the peritoneal cavity of mice.

\section{Conclusions}

In summary, we have developed the first single molecule 1,2-dioxetane ratiometric chemiluminescence probe for quantitative imaging of $\mathrm{pH}$ in animal tissue. This was synthetically achieved by attaching a $\mathrm{pH}$ sensitive carbofluorescein to the chemiluminescent acrylamide dioxetane scaffold via a piperazine linker. Ratio-pHCL-1 generates light through CIEEL decomposition, and concomitant pH dependent emission from the appended fluorophore through a CRET mechanism. Ratio-pHCL-1 is highly accurate in vitro, providing measurement of $\mathrm{pH}$ in biological ranges. Its ratiometric output is stable to confounding variables, and provides a similar response when collected through optical imaging methods. A pH dependent ratiometric emission is also reported in the peritoneal cavity of sacrificed mice, and we plan to conduct in vivo quantification of $\mathrm{pH}$ in live mouse models in future experiments. We report flux outputs of more than $10^{10} \mathrm{p} / \mathrm{s}$ from $20 \mu \mathrm{M}$ Ratio-pHCL-1 through biological tissue, which exceeds the photon flux of most reported chemiluminescence agents. This increase in brightness is achieved through use of an unmasked phenoxy dioxetane that provides instantaneous decomposition and light output. This shows a clear advantage to chemiluminescence detection using unmasked dioxetanes - they have the potential for much higher sensitivity in biological settings. This methodology can be applied to highly sensitive quantitation of other analytes, and has provided the foundation for in vivo ratiometric imaging with 1,2-dioxetanes.

\section{ASSOCIATED CONTENT}

\section{Supporting Information}

The Supporting Information is available free of charge on the ACS Publications website. 


\section{AUTHOR INFORMATION}

\section{Corresponding Author}

alippert@smu.edu

Present Addresses

\section{Author Contributions}

The manuscript was written through contributions of all authors. All authors have given approval to the final version of the manuscript.

\section{Funding Sources}

NSF CHE 1653474; P30 1CA142543 and 1S10RR024757.

\section{Notes}

The authors declare the following competing financial interest(s): A.R.L. discloses a financial stake in BioLum Sciences, LLC, a company developing chemiluminescence assays.

\section{ACKNOWLEDGMENT}

This work was supported by the National Science Foundation under CHE 1653474, and optical imaging was performed using an IVIS purchased under NIH 1S10RR024757 and supported by NIH P30 CA142543. We acknowledge Eric Weaver (UT Arlington) for assistance with mass spectrometry.

\section{REFERENCES}

(1) Hamm, L. L.; Nakhoul, N.; Hering-Smith, K. S. Acid-Base Homeostasis. Clin. J. Am. Soc. Nephrol. 2015, 10, 2232-2242.

(2) Weiner, I. D.; Hamm, L. L. Molecular Mechanisms of Renal Ammonia Transport. Annu. Rev. Physiol. 2007, 69, 317-340.

(3) Koeppen, B. M. The Kidney and Acid-Base Regulation. Adv. Physiol. Educ. 2009, 33, 275-281.

(4) Ruffin, V. A.; Salameh, A. I.; Boron, W. F.; Parker, M. D Intracellular $\mathrm{PH}$ Regulation by Acid-Base Transporters in Mammalian Neurons. Front. Physiol. 2014, 5, 1-11.

(5) Boron, W. F. Regulation of Intracellular PH. Adv. Physiol. Educ 2004, 28, 160-179.

(6) Aalkjaer, C.; Boedtkjer, E.; Choi, I.; Lee, S. Cation-Coupled Bicarbonate Transporters. Compr Physiol. 2014; 4. , 1605-1637.

(7) Aoi, W.; Marunaka, Y. Importance of PH Homeostasis in Metabolic Health and Diseases: Crucial Role of Membrane Proton Transport. Biomed Res. Int. 2014, 2014.

(8) Trachtenbarg, D. E. Diabetic Ketoacidosis. Am Fam Physician 2005, 71, 1705-1714.

(9) Boedtkjer, E.; Pedersen, S. F. The Acidic Tumor Microenvironment as a Driver of Cancer. Annu. Rev. Physiol. 2020, 82, 103-126.

(10) Heiden, M. G. V.; Cantley, L. C.; Thompson, C. B. Understanding the Warburg Effect: The Metabolic Requirements of Cell Proliferation. Science. 2009, 329, 1029-1033.

(11) Rohani, N.; Hao, L.; Alexis, M. S.; Joughin, B. A.; Krismer, K.; Moufarrej, M. N.; Soltis, A. R.; Lauffenburger, D. A.; Yaffe, M. B.; Burge, C. B.; et al. Acidification of Tumor at Stromal Boundaries Drives Transcriptome Alterations Associated with Aggressive Phenotypes. Cancer Res. 2019, 79, 1952-1966.

(12) Robey, I. F.; Baggett, B. K.; Kirkpatrick, N. D.; Roe, D. J.; Dosescu, J.; Sloane, B. F.; Hashim, A. I.; Morse, D. L.; Raghunand, N.; Gatenby, R. A.; et al. Bicarbonate Increases Tumor PH and Inhibits Spontaneous Metastases. Cancer Res. 2009, 69, 2260-2268.

(13) Jin, T.; Wang, P.; Jin, T.; Kim, S. G.; Kim, S. G. Enhancing Sensitivity of PH-Weighted MRI with Combination of Amide and Guanidyl CEST. Neuroimage 2017, 157, 341-350.

(14) Wu, Y.; Zhou, I. Y.; Igarashi, T.; Longo, D. L.; Aime, S.; Sun, P. Z. A Generalized Ratiometric Chemical Exchange Saturation Transfer (CEST) MRI Approach for Mapping Renal PH Using Iopamidol. Magn. Reson. Med. 2018, 79, 1553-1558.

(15) Pavuluri, K. D.; McMahon, M. T. PH Imaging Using Chemical Exchange Saturation Transfer (CEST) MRI. Isr. J. Chem. 2017,

57, 862-887.

Mason, R. P. Transmembrane PH Gradients In Vivo: Measurements Using Fluorinated Vitamin B6 Derivatives. Curr. Med. Chem. 1999, 6, 491-499.

Jähde, E.; Rajewsky, M. F. Sensitization of Clonogenic Malignant Cells to Hyperthermia by Glucose-Mediated, TumorSelective pH Reduction. J. Cancer Res. Clin. Oncol. 1982, 104, 23-30.

Engin, K.; Leeper, D. B.; Thistlethwaite, A. J.; Tupchong, L.; Phil, D.; McFarlane, J. D. Tumor Extracellular PH as a Prognostic Factor in Thermoradiotherapy. Int. J. Radiat. Oncol. Biol. Phys. 1994, 29, 125-132.

Aggarwal, K.; Khurana, J. M. Indeno-Furan Based Colorimetric and on-off Fluorescent pH Sensors. J. Photochem. Photobiol. A Chem. 2015, 307-308, 23-29.

Li, Z.; Li, L. J.; Sun, T.; Liu, L.; Xie, Z. Benzimidazole-BODIPY as Optical and Fluorometric pH Sensor. Dye. Pigm. 2016, 128, 165-169.

Qi, J.; Liu, D.; Liu, X.; Guan, S.; Shi, F.; Chang, H.; He, H.; Yang, G. Fluorescent $\mathrm{pH}$ Sensors for Broad-Range $\mathrm{pH}$ Measurement Based on a Single Fluorophore. Anal. Chem. 2015, 87, 58975904.

$\mathrm{Xu}, \mathrm{X}$. Y.; Yan, B. An Efficient and Sensitive Fluorescent pH Sensor Based on Amino Functional Metal-Organic Frameworks in Aqueous Environment. Dalt. Trans. 2016, 45, 7078-7084. Richardson, D. S.; Gregor, C.; Winter, F. R.; Urban, N. T.; Sahl, S. J.; Willig, K. I.; Hell, S. W. SRpHi Ratiometric pH Biosensors for Super-Resolution Microscopy. Nat. Commun. 2017, 8,577.

Hanson, G. T.; McAnaney, T. B.; Park, E. S.; Rendell, M. E. P.; Yarbrough, D. K.; Chu, S.; Xi, L.; Boxer, S. G.; Montrose, M. H.; Remington, S. J. Green Fluorescent Protein Variants as Ratiometric Dual Emission pH Sensors. 1. Structural Characterization and Preliminary Application. Biochemistry 2002, 41, 15477-15488.

Zhang, Y.; Xie, Q.; Robertson, J. B.; Johnson, C. H. pHlash: A New Genetically Encoded and Ratiometric Luminescence Sensor of Intracellular PH. PLoS One 2012, 7, 43072.

Pratiwi, F. W.; Hsia, C. H.; Kuo, C. W.; Yang, S. M.; Hwu, Y. K.; Chen, P. Construction of Single Fluorophore Ratiometric PH Sensors Using Dual-Emission Mn2+-Doped Quantum Dots. Biosens. Bioelectron. 2016, 84, 133-140.

Jin, T.; Sasaki, A.; Kinjo, M.; Miyazaki, J. A Quantum Dot-Based Ratiometric pH Sensor. Chem. Commun. 2010, 46, 2408-2410. Shi, W.; Li, X.; Ma, H. A Tunable Ratiometric pH Sensor Based on Carbon Nanodots for the Quantitative Measurement of the Intracellular pH of Whole Cells. Angew. Chem. Int. Ed. 2012, 51, 6432-6435.

Ma, T.; Hou, Y.; Zeng, J.; Liu, C.; Zhang, P.; Jing, L.; Shangguan, D.; Gao, M. Dual-Ratiometric Target-Triggered Fluorescent Probe for Simultaneous Quantitative Visualization of Tumor Microenvironment Protease Activity and $\mathrm{pH}$ in Vivo. J. Am. Chem. Soc. 2018, 140, 211-218.

Lei, J.; Wang, L.; Zhang, J. Ratiometric pH Sensor Based on Mesoporous Silica Nanoparticles and Förster Resonance Energy Transfer. Chem. Commun. 2010, 46, 8445-8447.

Augusto, F. A.; De Souza, G. A.; De Souza, S. P.; Khalid, M.; Baader, W. J. Efficiency of Electron Transfer Initiated Chemiluminescence. Photochem. Photobiol. 2013, 89, 1299 1317.

Vacher, M.; Fdez Galván, I.; Ding, B. W.; Schramm, S.; BerraudPache, R.; Naumov, P.; Ferré, N.; Liu, Y. J.; Navizet, I.; RocaSanjuán, D.; et al. Chemi- and Bioluminescence of Cyclic Peroxides. Chem. Rev. 2018, 118, 6927-6974.

Bezner, B. J.; Ryan, L. S.; Lippert, A. R. Reaction-Based Luminescent Probes for Reactive Sulfur, Oxygen, and Nitrogen Species: Analytical Techniques and Recent Progress. Anal. Chem. 2020, 92, 309-326.

Ryan, L. S.; Gerberich, J.; Cao, J.; An, W.; Jenkins, B. A.; Mason, R. P.; Lippert, A. R. Kinetics-Based Measurement of Hypoxia in Living Cells and Animals Using an Acetoxymethyl Ester Chemiluminescent Probe. ACS Sens. 2019, 4, 1391-1398.

Cao, J.; Campbell, J.; Liu, L.; Mason, R. P.; Lippert, A. R. In Vivo Chemiluminescent Imaging Agents for Nitroreductase and Tissue Oxygenation. Anal. Chem. 2016, 88, 4995-5002.

Sun, J.; Hu, Z.; Wang, R.; Zhang, S.; Zhang, X. A Highly 
Sensitive Chemiluminescent Probe for Detecting Nitroreductase and Imaging in Living Animals. Anal. Chem. 2019, 91, 13841390.

Cao, J.; Lopez, R.; Thacker, J. M.; Moon, J. Y.; Jiang, C.; Morris, S. N. S.; Bauer, J. H.; Tao, P.; Mason, R. P.; Lippert, A. R. Chemiluminescent Probes for Imaging H2S in Living Animals. Chem. Sci. 2015, 6, 1979-1985.

(38) Cao, J.; An, W.; Reeves, A. G.; Lippert, A. R. A Chemiluminescent Probe for Cellular Peroxynitrite Using a SelfImmolative Oxidative Decarbonylation Reaction. Chem. Sci. 2018, 9, 2552-2558.

(39) An, W.; Ryan, L. S.; Reeves, A. G.; Bruemmer, K. J.; Mouhaffel, L.; Gerberich, J. L.; Winters, A.; Mason, R. P.; Lippert, A. R. A Chemiluminescent Probe for HNO Quantification and Real-Time Monitoring in Living Cells. Angew. Chem. Int. Ed. 2019, 58, 1361-1365.

(40) Shabat, D.; Roth-Konforti, M.; Bauer, C. Unprecedented Sensitivity in a Probe for Detection and Imaging of Cathepsin B: Chemiluminescence Microscopy Cell Images of NativelyExpressed Enzyme. Angew. Chem. Int. Ed. 2017, 56, 1563315638.

(41) Liu, L.; Mason, R. P. Imaging $\beta$-Galactosidase Activity in Human Tumor Xenografts and Transgenic Mice Using a Chemiluminescent Substrate. PLoS One. 2010, 5, e12024.

(42) Zhang, Y.; Yan, C.; Wang, C.; Guo, Z.; Liu, X.; Zhu, W. H. A Sequential Dual-Lock Strategy for Photoactivatable Chemiluminescent Probes Enabling Bright Duplex Optical Imaging. Angew. Chem. Int. Ed. 2020, 59, 2-10.

(43) Bruemmer, K. J.; Green, O.; Su, T. A.; Shabat, D.; Chang, C. J. Chemiluminescent Probes for Activity-Based Sensing of Formaldehyde Released from Folate Degradation in Living Mice. Angew. Chem. Int. Ed. 2018, 57, 7508-7512.

(44) Huang, J.; Lyu, Y.; Li, J.; Cheng, P.; Jiang, Y.; Pu, K. A RenalClearable Duplex Optical Reporter for Real-Time Imaging of Contrast-Induced Acute Kidney Injury. Angew. Chem. Int. Ed. 2019, 58, 17796-17804.

(45) Gnaim, S.; Scomparin, A.; Das, S.; Blau, R.; Satchi-Fainaro, R.; Shabat, D. Direct Real-Time Monitoring of Prodrug Activation by Chemiluminescence. Angew. Chem.Int. Ed. 2018, 57, 90339037.

(46) Roth-Konforti, M.; Green, O.; Hupfeld, M.; Fieseler, L.; Heinrich, N.; Ihssen, J.; Vorberg, R.; Wick, L.; Spitz, U.; Shabat, D. Ultrasensitive Detection of Salmonella and Listeria Monocytogenes by Small-Molecule Chemiluminescence Probes. Angew. Chem. Int. Ed. 2019, 131, 10469-10475.

(47) Shabat, D.; Das, S.; Ihssen, J.; Wick, L.; Spitz, U. Chemiluminescence Carbapenem-based Molecular Probe for Detection of Carbapenemase Activity in Live Bacteria. Chem. Eur. J. 2020, 26, 3647-3652.

(48) Son, S.; Won, M.; Green, O.; Hananya, N.; Sharma, A.; Jeon, Y.; Kwak, J. H.; Sessler, J. L.; Shabat, D.; Kim, J. S. Chemiluminescent Probe for the In Vitro and In Vivo Imaging of Cancers Over-Expressing NQO1. Angew. Chem. Int. Ed. 2019, 58, 1739-1743.

(49) An, R.; Wei, S.; Huang, Z.; Liu, F.; Ye, D. An Activatable Chemiluminescent Probe for Sensitive Detection of $\gamma$-Glutamyl Transpeptidase Activity in Vivo. Anal. Chem. 2019, 91, 1363913646.

(50) Hananya, N.; Press, O.; Das, A.; Scomparin, A.; Satchi-Fainaro, R.; Sagi, I.; Shabat, D. Persistent Chemiluminescent Glow of Phenoxy-Dioxetane Luminophore Enables Unique CRET-Based Detection of Proteases. Chem. Eur. J. 2019, 25, 14679-14687.

(51) Miranda-Apodaca, J.; Hananya, N.; Velázquez-Campoy, A.; Shabat, D.; Arellano, J. B. Emissive Enhancement of the Singlet Oxygen Chemiluminescence Probe after Binding to Bovine Serum Albumin. Molecules 2019, 24.

(52) Hananya, N.; Green, O.; Blau, R.; Satchi-Fainaro, R.; Shabat, D. A Highly Efficient Chemiluminescence Probe for the Detection of Singlet Oxygen in Living Cells. Angew. Chem. Int. Ed. 2017, 56, 11793-11796.

(53) Ryan, L. S.; Lippert, A. R. Ultrasensitive Chemiluminescent Detection of Cathepsin B: Insights into the New Frontier of Chemiluminescent Imaging. Angew. Chem. Int. Ed. 2018, 57, 622-624.
Chan, J. A Bioreducible N-Oxide-Based Probe for Photoacoustic Imaging of Hypoxia. Nat. Commun. 2017, 8.

Knox, H. J.; Kim, T. W.; Zhu, Z.; Chan, J. Photophysical Tuning of N -Oxide-Based Probes Enables Ratiometric Photoacoustic Imaging of Tumor Hypoxia. ACS Chem. Biol. 2018, 13, 1838 1843 .

(56) Zhou, E. Y.; Knox, H. J.; Liu, C.; Zhao, W.; Chan, J. A Conformationally Restricted Aza-BODIPY Platform for Stimulus-Responsive Probes with Enhanced Photoacoustic Properties. J. Am. Chem. Soc. 2019, 141, 17601-17609.

(57) McDonnell, S. O.; O'Shea, D. F. Near-Infrared Sensing Properties of Dimethlyamino-Substituted BF 2Azadipyrromethenes. Org. Lett. 2006, 8, 3493-3496.

(58) Grimm, J. B.; Sung, A. J.; Legant, W. R.; Hulamm, P.; Matlosz, S. M.; Betzig, E.; Lavis, L. D. Carbofluoresceins and Carborhodamines as Scaffolds for High-Contrast Fluorogenic Probes. ACS Chem. Biol. 2013, 8, 1303-1310.

(59) Grimm, J. B.; Gruber, T. D.; Ortiz, G.; Brown, T. A.; Lavis, L. D. Virginia Orange: A Versatile, Red-Shifted Fluorescein Scaffold for Single- And Dual-Input Fluorogenic Probes. Bioconjug. Chem. 2016, 27, 474-480.

(60) Grimm, J. B.; English, B. P.; Choi, H.; Muthusamy, A. K.; Mehl, B. P.; Dong, P.; Brown, T. A.; Lippincott-Schwartz, J.; Liu, Z.; Lionnet, T.; et al. Bright Photoactivatable Fluorophores for Single-Molecule Imaging. Nat. Methods 2016, 13, 985-988.

(61) Grimm, J. B.; Brown, T. A.; Tkachuk, A. N.; Lavis, L. D. General Synthetic Method for Si-Fluoresceins and Si-Rhodamines. ACS Cent. Sci. 2017, 3, 975-985.

(62) Zhou, X.; Lai, R.; Beck, J. R.; Li, H.; Stains, C. I. Nebraska Red: A Phosphinate-Based near-Infrared Fluorophore Scaffold for Chemical Biology Applications. Chem. Commun. 2016, 52, 12290-12293.

(63) Fang, Y.; Good, G. N.; Zhou, X.; Stains, C. I.; Li, R. PhosphinateContaining Rhodol and Fluorescein Scaffolds for the Development of Bioprobes. Chem. Commun. 2019, 55, 59625965.

(64) Michie, M. S.; Götz, R.; Franke, C.; Bowler, M.; Kumari, N.; Magidson, V.; Levitus, M.; Loncarek, J.; Sauer, M.; Schnermann, M. J. Cyanine Conformational Restraint in the Far-Red Range. J. Am. Chem. Soc. 2017, 139, 12406-12409.

(65) Cosco, E. D.; Caram, J. R.; Bruns, O. T.; Franke, D.; Day, R. A.; Farr, E. P.; Bawendi, M. G.; Sletten, E. M. Flavylium Polymethine Fluorophores for Near- and Shortwave Infrared Imaging. Angew. Chem. Int. Ed. 2017, 56, 13126-13129.

(66) Pengshung, M.; Kwon, J.; Sletten, E.; Pengshung, M.; Kwon, J.; Sletten, E. M. Bathochromically Shifted Polymethine Dyes Through Silicon Incorporation. Chemrxiv 2019.

(67) Green, O.; Eilon, T.; Hananya, N.; Gutkin, S.; Bauer, C. R.; Shabat, D. Opening a Gateway for Chemiluminescence Cell Imaging: Distinctive Methodology for Design of Bright Chemiluminescent Dioxetane Probes. ACS Cent. Sci. 2017, 3, 349-358.

(68) Green, O.; Gnaim, S.; Blau, R.; Eldar-Boock, A.; Satchi-Fainaro, R.; Shabat, D. Near-Infrared Dioxetane Luminophores with Direct Chemiluminescence Emission Mode. J. Am. Chem. Soc. 2017, 139, 13243-13248.

(69) Rainey, K. H.; Patterson, G. H. Photoswitching FRET to Monitor Protein-Protein Interactions. Proc. Natl. Acad. Sci. 2019, 116, 864-873.

(70) Chung, C. Y. S.; Posimo, J. M.; Lee, S.; Tsang, T.; Davis, J. M.; Brady, D. C.; Chang, C. J. Activity-Based Ratiometric FRET Probe Reveals Oncogene-Driven Changes in Labile Copper Pools Induced by Altered Glutathione Metabolism. Proc. Natl. Acad. Sci. 2019, 116, 18285-18294.

(71) Albers, A. E.; Okreglak, V. S.; Chang, C. J. A FRET-Based Approach to Ratiometric Fluorescence Detection of Hydrogen Peroxide. J. Am. Chem. Soc. 2006, 128, 9640-9641.

(72) Zhang, X.; Xiao, Y.; Qian, X. A Ratiometric Fluorescent Probe Based on FRET for Imaging $\mathrm{Hg}^{2+}$ Ions in Living Cells. Angew. Chem. Int. Ed. 2008, 47, 8025-8029.

(73) Ai, H. W.; Hazelwood, K. L.; Davidson, M. W.; Campbell, R. E. Fluorescent Protein FRET Pairs for Ratiometric Imaging of Dual Biosensors. Nat. Methods 2008, 5, 401-403.

(74) Hananya, N.; Eldar Boock, A.; Bauer, C. R.; Satchi-Fainaro, R.; Shabat, D. Remarkable Enhancement of Chemiluminescent 
Signal by Dioxetane-Fluorophore Conjugates: Turn-ON Chemiluminescence Probes with Color Modulation for Sensing and Imaging. J. Am. Chem. Soc. 2016, 138, 13438-13446.

(75)

Hananya, N.; Press, O.; Das, A.; Scomparin, A.; Satchi-Fainaro, R.; Sagi, I.; Shabat, D. Persistent Chemiluminescent Glow of Phenoxy-Dioxetane Luminophore Enables Unique CRET-Based Detection of Proteases. Chem. Eur. J. 2019, 25, 14679-14687.

(76)

An, W.; Mason, R. P.; Lippert, A. R. Energy Transfer Chemiluminescence for Ratiometric PH Imaging. Org. Biomol. Chem. 2018, 16, 4176-4182.
(77) Lumpi, D.; Wagner, C.; Schöpf, M.; Horkel, E.; Ramer, G.; Lendl, B.; Fröhlich, J. Fibre Optic ATR-IR Spectroscopy at Cryogenic Temperatures: In-Line Reaction Monitoring on Organolithium Compounds. Chem. Commun. 2012, 48, 24512453.

(78) Kommreddy, A.; Bowsher, M. S.; Gunna, M. R.; Botha, K.; Vinod, T. K. Expedient Synthesis and Solvent Dependent Oxidation Behavior of a Water-Soluble IBX Derivative. Tetrahedron Lett. 2008, 49, 4378-4382. 


\title{
Supporting Information for: Quantitative ratiometric $\mathbf{p H}$ imaging using a 1,2-dioxetane chemiluminescence resonance energy transfer sensor
}

\author{
Lucas S. Ryan, ${ }^{\dagger}$ Jeni Gerberich, ${ }^{\#}$ Uroob Haris, ${ }^{\dagger}$ Ralph P. Mason, ${ }^{\#}$ and Alexander R. Lippert $*, \dagger, \S, \uparrow$ \\ ${ }^{\dagger}$ Department of Chemistry, ${ }^{\S}$ Center for Drug Discovery, Design, and Delivery (CD4), and ${ }^{\mathbb{I}}$ Center for Global Health \\ Impact (CGHI), Southern Methodist University, Dallas, TX, 75275-0314. *E-mail: alippert@smu.edu. Fax: 214-768- \\ 4089. \\ \#Prognostic Imaging Research Laboratory (PIRL), Pre-clinical Imaging Section, Department of Radiology, UT \\ Southwestern Medical Center, Dallas, TX 75390-9058, USA.
}

\section{Supporting Information:}

1. General synthetic materials and methods

2. Ratio-pHCL-1 in vitro characterization

3. Cell culture and biological studies

4. Ratiometric pH imaging

5. Supplementary references

6. Reported Spectra
Page S1

Page S11

Page S13

Page S14

Page S15

Page S16

1. General synthetic materials and methods All reactions were performed in dried glassware under an atmosphere of dry $\mathrm{N}_{2}$. Silica gel P60 (SiliCycle) was used for column chromatography and SiliCycle 60 F254 silica gel (precoated sheets, $0.25 \mathrm{~mm}$ thick) was used for analytical thin layer chromatography. Plates were visualized by fluorescence quenching under UV light. Other reagents were purchased from Sigma-Aldrich (St. Louis, MO), Alfa Aesar (Ward Hill, MA), EMD Millipore (Billerica, MA), Oakwood Chemical (West Columbia, SC), and Cayman Chemical (Ann Arbor, MI) and used without further purification. ${ }^{1} \mathrm{H}$ NMR for compounds and ${ }^{13} \mathrm{C}$ NMR for compounds were collected on a Bruker $400 \mathrm{MHz}$ or a JEOL $500 \mathrm{MHz}$ spectrometer in the Department of Chemistry at Southern Methodist University. ${ }^{1} \mathrm{H}$ and ${ }^{13} \mathrm{C}$ NMR spectra for characterization of new compounds and monitoring reactions were collected in $\mathrm{CDCl}_{3}$, acetone-d6, methanol-d4, or DMSO-d6 (Cambridge Isotope Laboratories, Cambridge, MA). All chemical shifts are reported in the standard notation of parts per million using the peak of residual proton signals of the deuterated solvent as an internal reference. Coupling constant units are in Hertz $(\mathrm{Hz})$ Splitting patterns are indicated as follows: br, broad; s, singlet; d, doublet; $\mathrm{t}$, 
triplet; q, quartet; m, multiplet; dd, doublet of doublets; dt, doublet of triplets. High resolution mass spectroscopy was performed on a Shimadzu IT-TOF (ESI source) at the Shimadzu Center for Advanced Analytical Chemistry at the University of Texas, Arlington, and low-resolution mass spectrometry was performed on an Advion Expression $^{\mathrm{L}}$ CMS (ESI source) at Southern Methodist University.

Scheme S1. Synthetic procedures for compounds 2, S6, and 8.

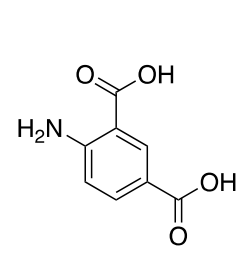

S1

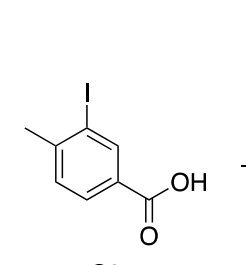

S3

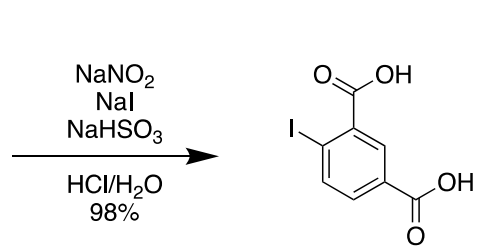

S2
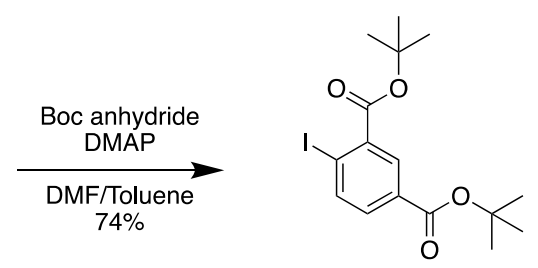

2
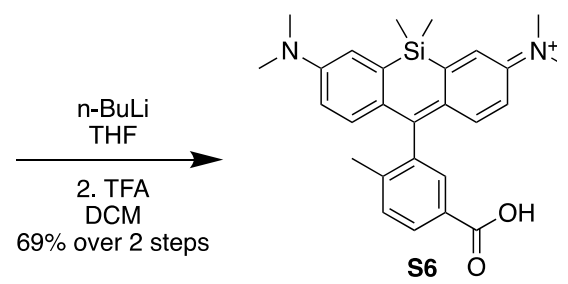

$69 \%$ over 2 steps

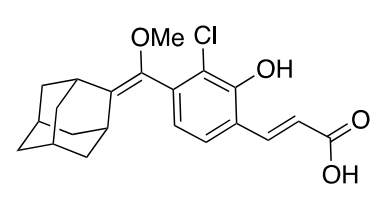

S7
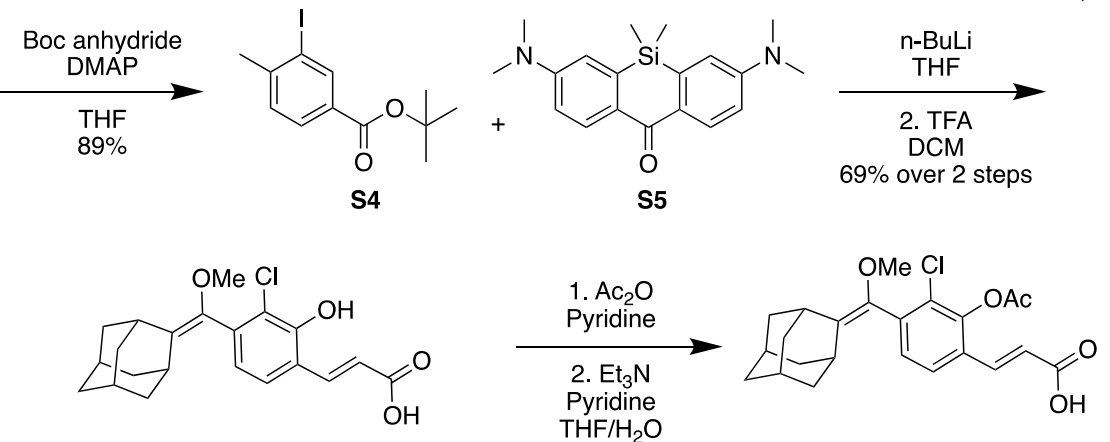

8<smiles>O=C(O)c1ccc(I)c(C(=O)O)c1</smiles>

S2

5-iodoisophthalic acid (S2). ${ }^{1}$ In a $1 \mathrm{~L}$ roundbottom flask equipped with a stir bar, 2aminoterephthalic acid (50 mmol, $9.06 \mathrm{~g}, 1.0$ equiv) was suspended in $300 \mathrm{~mL} 5.8 \mathrm{M} \mathrm{HCl}$ at $0{ }^{\circ} \mathrm{C}$ under $\mathrm{N}_{2}$ atmosphere. Sodium nitrite (125 mmol, $8.63 \mathrm{~g}, 2.5$ equiv) was dissolved in $100 \mathrm{~mL} \mathrm{H}_{2} \mathrm{O}$ and added dropwise via addition funnel over $1 \mathrm{hr}$. In a 2L roundbottom flask, sodium iodide (300 mmol, $45 \mathrm{~g}, 6.0$ equiv) was dissolved. The contents of the $1 \mathrm{~L}$ flask were then added to the sodium 
iodide solution, upon which the reaction smoked and turned black. The reaction was stirred for another $18 \mathrm{hr}$. The reaction was then quenched with sodium bisulfite, and $450 \mathrm{~mL}$ DCM was added to the mixture. The solution was then filtered with filter paper, and the resulting brown solid was left to dry overnight, yielding 2-iodoterepthalic acid (48.94 mmol $14.29 \mathrm{~g}, 98 \%)$, which was used in the next step without further purification.

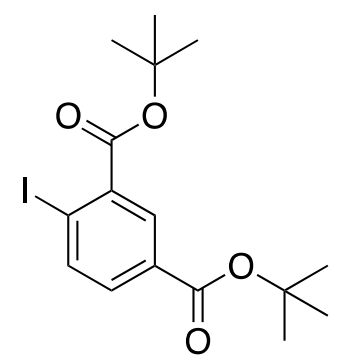

2

di-tert-butyl 5-iodoisophthalate (2). ${ }^{1}$ in a $100 \mathrm{~mL}$ roundbottom flask equipped with a stir bar under $\mathrm{N}_{2}$ atmosphere, 2-iodoterephthalic acid (7.23 mmol, $2111 \mathrm{mg}, 1.0$ equiv) and DMAP (1.44 mmol, $176 \mathrm{mg}, 0.2$ equiv) were dissolved in $2 \mathrm{~mL}$ DMF and $20 \mathrm{~mL}$ toluene. Di-tert-butyl dicarbonate ( $21.69 \mathrm{mmol}, 4734 \mathrm{mg}, 3.0$ equiv) was added. The reaction was heated to $80{ }^{\circ} \mathrm{C}$ and stirred for $30 \mathrm{~min} .1$ equiv Boc anhydride was added to drive the reaction to completion and stirred for 30 more min. Upon completion, the reaction was allowed to cool to RT, washed with sat. $\mathrm{NH}_{4} \mathrm{Cl}$, eluted with $3 \times 30 \mathrm{~mL}$ EtOAc, dried with $\mathrm{Na}_{2} \mathrm{SO}_{4}$, and concentrated under reduced pressure. Column chromatography in 5\% EtOAc/Hexanes yielded compound 2 (5.35 mmol, 74\%) as a yellow oil. ${ }^{1} \mathrm{H}$ NMR $\left(400 \mathrm{MHz}, \mathrm{CDCl}_{3}\right) \delta 8.52(\mathrm{~d}, 1 \mathrm{H}, J=1.2 \mathrm{~Hz}), 7.97\left(\mathrm{dd}, 1 \mathrm{H}, J_{1}=8.0 \mathrm{~Hz}\right.$, $\left.J_{2}=1.2 \mathrm{~Hz}\right), 7.67(\mathrm{~d}, 1 \mathrm{H}, J=8.0 \mathrm{~Hz}), 1.65(\mathrm{~s}, 9 \mathrm{H}), 1.62(\mathrm{~s}, 9 \mathrm{H})$.

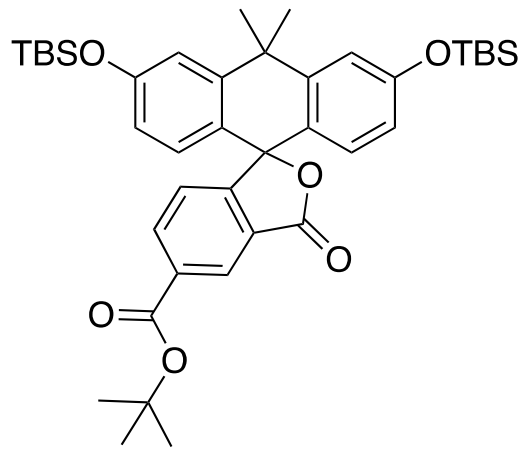




\section{tert-butyl-3,6-bis((tert-butyldimethylsilyl)oxy)-10,10-dimethyl-3' -oxo-3'H,10H-}

spiro[anthracene-9,1'-isobenzofuran]-5'-carboxylate (3). ${ }^{2}$ In a $25 \mathrm{~mL}$ oven-dried roundbottom flask equipped with a stir bar, compound 1 ( $0.46 \mathrm{mmol}, 220 \mathrm{mg}, 1.0$ equiv) and compound 2 (1.6 mmol, $647 \mathrm{mg}, 3.5$ equiv) were added, and purged 3x with $\mathrm{N}_{2} .6 \mathrm{~mL}$ anhydrous THF was then added, and the reaction contents were cooled to $0{ }^{\circ} \mathrm{C}$. $2.6 \mathrm{M} \mathrm{n}$-BuLi (1.76 mmol, $0.68 \mathrm{~mL}, 3.85$ equiv) was added dropwise, over which period the reaction changed from light yellow to deep purple in color. The reaction was stirred $10 \mathrm{~min}$, then allowed to warm to RT and stirred for $2 \mathrm{hr}$. The reaction was then quenched with $5 \mathrm{~mL} \mathrm{H}_{2} \mathrm{O}$, washed with brine/1M HCl, eluted $2 \mathrm{x}$ with 20 mL EtOAc, dried with $\mathrm{Na}_{2} \mathrm{SO}_{4}$, filtered, and concentrated under reduced pressure. Column chromatography (3-5\% EtOAc/Hexanes) yielded compound 3 (0.231 mmol, $109 \mathrm{mg}, 35 \%)$ as a white solid. ${ }^{1} \mathrm{H}$ NMR $\left(400 \mathrm{MHz}, \mathrm{CDCl}_{3}\right) \delta 8.17(\mathrm{dd}, 1 \mathrm{H}, J=8.0 \mathrm{~Hz}, J=1.2 \mathrm{~Hz}), 8.04(\mathrm{~d}, 1 \mathrm{H}, J=$ $8.0 \mathrm{~Hz}), 7.64(\mathrm{~s}, 1 \mathrm{H}), 7.10(\mathrm{~s}, 2 \mathrm{H}), 6.62(\mathrm{~d}, 4 \mathrm{H}, J=1.2 \mathrm{~Hz}), 1.83(\mathrm{~s}, 3 \mathrm{H}), 1.74(\mathrm{~s}, 3 \mathrm{H}), 1.56(\mathrm{~s}, 9 \mathrm{H})$, $1.01(\mathrm{~s}, 18 \mathrm{H}), 0.24(\mathrm{~s}, 12 \mathrm{H})$.

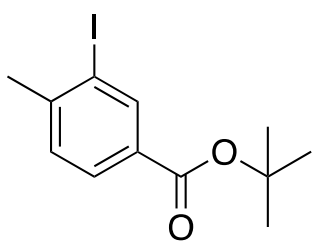

S4

tert-butyl 3-iodo-4-methylbenzoate (S4). 3-Iodo-4-methylbenzoic acid (S3) (7.63 mmol, $2.00 \mathrm{~g}$, 1.0 equiv), di-tert-butyl dicarbonate ( $19.0 \mathrm{mmol}, 4.10 \mathrm{~g}, 2.5$ equiv), and DMAP (1.53 mmol, 0.19 $\mathrm{g}, 0.2$ equiv) were combined in a roundbottom flask and dissolved in $20 \mathrm{~mL}$ anhydrous THF. The reaction was heated to $60{ }^{\circ} \mathrm{C}$ and stirred under reflux for 20 hours. After cooling the reaction to RT, the solvent was evaporated off under reduced pressure and the residue was dissolved in $\mathrm{Et}_{2} \mathrm{O}$, which was then washed with sat. aq. $\mathrm{NaHCO}_{3}(\mathrm{x} 3), \mathrm{H}_{2} \mathrm{O}$, and brine. The organic layer was dried over $\mathrm{Na}_{2} \mathrm{SO}_{4}$ and concentrated. Purification via column chromatography with $10 \%$ EtOAc/Hexanes yielded the product as a golden oil (6.82 mmol, $2.17 \mathrm{~g}, 89 \%) .{ }^{1} \mathrm{H} \mathrm{NMR}(500 \mathrm{MHz}$, $\left.\mathrm{CDCl}_{3}\right) \delta 8.36(\mathrm{~d}, J=1.7 \mathrm{~Hz}, 1 \mathrm{H}), 7.81(\mathrm{dd}, J=1.7,8.0 \mathrm{~Hz}, 1 \mathrm{H}), 7.22(\mathrm{~d}, J=8.0 \mathrm{~Hz}, 1 \mathrm{H}), 2.42(\mathrm{~s}$, 3H), 1.55 (s, 9H); ${ }^{13} \mathrm{C}$ NMR (125 MHz, $\left.\mathrm{CDCl}_{3}\right) \delta 164.23,146.18,139.90,131.25,129.40,129.23$, $100.51,81.41,81.02,28.40,28.24,27.97$. 


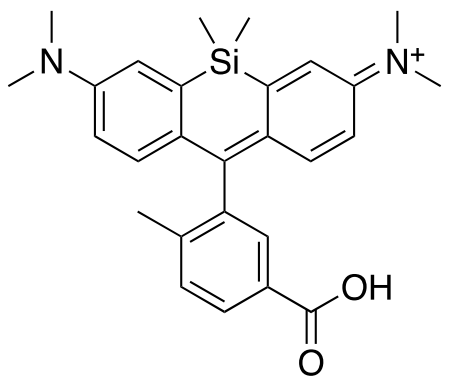

S6

\section{N-(10-(5-carboxy-2-methylphenyl)-7-(dimethylamino)-5,5-dimethyldibenzo[b,e]silin-3(5H)-} ylidene)-N-methylmethanaminium (S6). Compound $\mathbf{S 4}(4.93 \mathrm{mmol}, 1.57 \mathrm{~g}, 4.0$ equiv) and silicon anthrone $\mathbf{S 5}^{3}$ (1.23 mmol, $0.400 \mathrm{~g}, 1.0$ equiv), prepared according to literature procedure, were added to an oven dried flask, which was evacuated and flushed with nitrogen. Dry THF (25 $\mathrm{mL}$ ) was added to the flask and the reaction was stirred until starting materials dissolved. The reaction was then cooled to $0{ }^{\circ} \mathrm{C}$, and $1.5 \mathrm{M} n$-BuLi in hexanes $(5.25 \mathrm{mmol}, 3.5 \mathrm{~mL}, 4.2$ equiv) was added dropwise, and a color change from yellow to orange was observed. The reaction was stirred for an additional 3 hours, allowing the temperature to rise to RT. TLC in 15\% EtOAc/Hexanes indicated disappearance of the anthrone starting material and formation of a deep blue colored product. $1 \mathrm{M} \mathrm{HCl}$ was then added to quench the reaction, resulting is an intense blue solution of $\mathrm{pH}=1$. Saturated aqueous $\mathrm{NaHCO}_{3}$ was added to neutralize the reaction, which was then extracted with DCM. The blue organic layer was washed with brine, dried over $\mathrm{Na}_{2} \mathrm{SO}_{4}$ and concentrated to a blue solid. This crude tert-butyl ester product was dissolved in DCM (15 mL) and trifluoroacetic acid $(3 \mathrm{~mL})$ was added. The reaction was stirred at RT for 3.5 hours, while monitoring product formation via mass spectroscopy. The volatiles were then evaporated under reduced pressure. The product was isolated using column chromatography with $10 \% \mathrm{MeOH} / \mathrm{DCM}$ to obtain S6 as a blue solid (0.851 mmol, $0.377 \mathrm{~g}, 69 \%) .{ }^{1} \mathrm{H}$ NMR $\left(500 \mathrm{MHz}, \mathrm{CD}_{3} \mathrm{OD}\right) \delta 8.10(\mathrm{dd}$, $J=2.3,8.0 \mathrm{~Hz}, 1 \mathrm{H}), 7.72(\mathrm{~d}, J=1.7 \mathrm{~Hz}, 1 \mathrm{H}), 7.53(\mathrm{~d}, J=8.0 \mathrm{~Hz}, 1 \mathrm{H}), 7.37$ (d, $J=2.3 \mathrm{~Hz}, 2 \mathrm{H})$, $7.02(\mathrm{~d}, J=9.7 \mathrm{~Hz}, 2 \mathrm{H}), 6.77$ (dd, $J=2.9,9.7 \mathrm{~Hz}, 2 \mathrm{H}), 3.34(\mathrm{~s}, 12 \mathrm{H}), 2.10(\mathrm{~s}, 3 \mathrm{H}), 0.62(\mathrm{~s}, 3 \mathrm{H})$, $0.60(\mathrm{~s}, 3 \mathrm{H}) ;{ }^{13} \mathrm{C} \mathrm{NMR}\left(125 \mathrm{MHz}, \mathrm{CD}_{3} \mathrm{OD}\right) \delta 169.05,168.86,155.78,149.51,142.60,141.93$, $140.34,131.72,131.23,131.14,129.78,128.28,122.35,115.41,40.94,19.65,-1.10,-1.31$. 


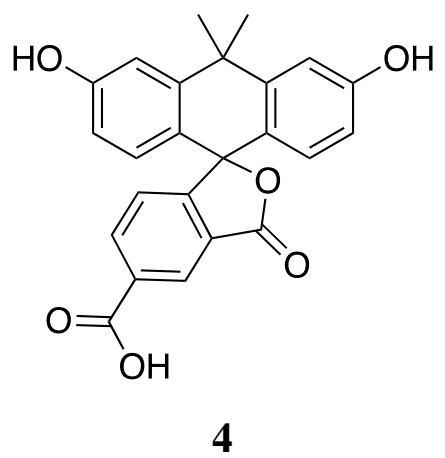

\section{3,6-dihydroxy-10,10-dimethyl-3'-oxo-3'H,10H-spiro[anthracene-9,1'-isobenzofuran]-5'-} carboxylic acid (4). ${ }^{2}$ In a 20 dram vial equipped with a stir bar, Compound $3(0.278 \mathrm{mmol}, 191$ $\mathrm{mg}$ ) was dissolved in $10 \mathrm{~mL}$ DCM. $2 \mathrm{~mL}$ TFA was added, and the reaction was stirred at RT under $\mathrm{N}_{2}$ atmosphere for $6 \mathrm{hr}$. Upon completion of the reaction as determined by TLC, the reaction was evaporated onto silica gel. Column chromatography (5\% MeOH/DCM, 1\% AcOH) afforded compound $4(0.189 \mathrm{mmol}, 76 \mathrm{mg}, 68 \%)$ as a red-orange solid. ${ }^{1} \mathrm{H}$ NMR (400 MHz, Acetone-D6) $\delta 8.29(\mathrm{~d}, 1 \mathrm{H}, J=8.0 \mathrm{~Hz}), 8.10(\mathrm{~d}, 1 \mathrm{H}, J=8.0 \mathrm{~Hz}), 7.67(\mathrm{~s}, 1 \mathrm{H}), 7.22(\mathrm{~d}, 2 \mathrm{H}, J=2.4 \mathrm{~Hz}), 6.71$ $(\mathrm{dd}, 2 \mathrm{H}, J=8.8 \mathrm{~Hz}, J=2.4 \mathrm{~Hz}), 6.65(\mathrm{~d}, 2 \mathrm{H}, J=8.8 \mathrm{~Hz}) ;{ }^{13} \mathrm{C}$ NMR $(100 \mathrm{MHz}$, Acetone-D6) $\delta$ 171.8, 169.0, 158.1, 155.7, 147.1, 130.5, 129.8, 129.3, 125.0, 124.7, 122.3, 114.9, 112.8, 86.5, 38.0, 34.2, 32.6, 19.7; HRMS calcd for $\mathrm{C}_{24} \mathrm{H}_{18} \mathrm{O}_{6}[\mathrm{M}+\mathrm{H}]^{+} 403.1176$, found 403.1163 .

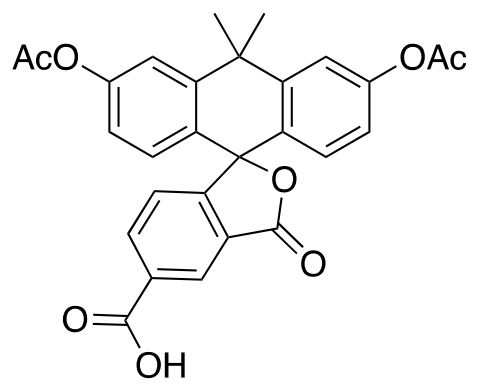

5

\section{3,6-diacetoxy-10,10-dimethyl-3'-oxo-3' H,10H-spiro[anthracene-9,1'-isobenzofuran]-5'-}

carboxylic acid (5). ${ }^{2}$ Compound 4 ( $0.189 \mathrm{mmol}, 76 \mathrm{mg}, 1.0$ equiv) was dissolved in $2 \mathrm{~mL} \mathrm{Ac}_{2} \mathrm{O}$ in a $20 \mathrm{~mL}$ roundbottom flask equipped with a stir bar. Pyridine $(0.982 \mathrm{mmol}, 76 \mu \mathrm{L}, 5.0$ equiv $)$ was added. The reaction was heated to $80^{\circ} \mathrm{C}$ and stirred for $1 \mathrm{hr}$ until TLC showed disappearance of starting material, and appearance of two spots, indicating a mixture of the generated mixed anhydride and free acid. The crude mixture was washed in $1 \mathrm{M} \mathrm{HCl}$, eluted with $2 \times 10 \mathrm{~mL} \mathrm{DCM}$, dried with $\mathrm{Na}_{2} \mathrm{SO}_{4}$, and concentrated under reduced pressure. The crude was then dissolved in 10 
$\mathrm{mL} \mathrm{1:1} \mathrm{THF} \mathrm{H}_{2} \mathrm{O}$ mixture. Pyridine (0.982 mmol, $76 \mu \mathrm{L}, 5.0$ equiv) and $\mathrm{Et}_{3} \mathrm{~N}$ (0.189 mmol, 30 $\mu \mathrm{L}, 1.0$ equiv) was added. The reaction was heated to $80^{\circ} \mathrm{C}$ and stirred for $1 \mathrm{hr}$, at which point TLC showed disappearance of the mixed anhydride. Column chromatography in 50\% EtOAc/Hexanes and 1\% AcOH yielded 5 (0.121 mmol, $59 \mathrm{mg}, 64 \%)$ as a white foam. ${ }^{1} \mathrm{H}$ NMR $\left(400 \mathrm{MHz}, \mathrm{CDCl}_{3}\right) \delta 8.30(\mathrm{~d}, 1 \mathrm{H}, J=8.0 \mathrm{~Hz}), 8.12(\mathrm{~d}, 1 \mathrm{H}, J=8.0 \mathrm{~Hz}), 7.75(\mathrm{~s}, 1 \mathrm{H}) 7.40(\mathrm{~d}, 1 \mathrm{H}$, $J=1.6 \mathrm{~Hz}), 7.40(\mathrm{~s}, 1 \mathrm{H}), 6.92(\mathrm{dd}, 2 \mathrm{H}, J=8.8 \mathrm{~Hz}, J=2.4 \mathrm{~Hz}), 6.76(\mathrm{~d}, 1 \mathrm{H}, J=8.8 \mathrm{~Hz}), 2.33(\mathrm{~s}$, $6 \mathrm{H}), 1.87$ (s, 3H), 1.77(s, 3H); ${ }^{13} \mathrm{C}$ NMR (100 MHz, $\left.\mathrm{CDCl}_{3}\right) \delta$ 169.4, 169.2, 169.2, 154.7, 141.5, 146.7, 135.8, 131.3, 130.1, 129.1, 128.1, 125.7, 125.6, 120.7, 119.5, 85.7, 38.6, 34.9, 32.8, 29.1, 21.2; HRMS calcd for $\mathrm{C}_{28} \mathrm{H}_{22} \mathrm{O}_{8}[\mathrm{M}+\mathrm{Na}]^{+}$509.1207, found 509.1218.

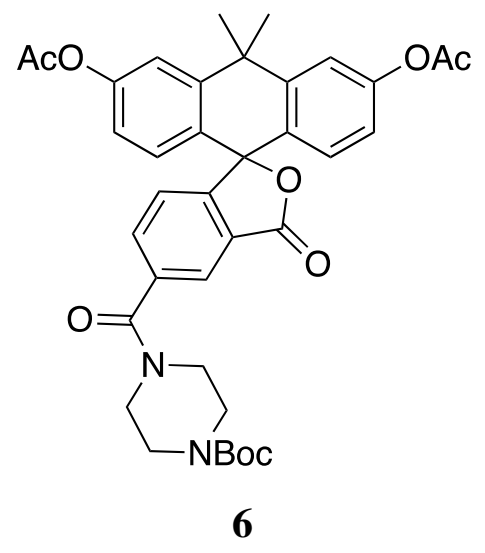

5' -(4-(tert-butoxycarbonyl)piperazine-1-carbonyl)-10,10-dimethyl-3'-oxo-3' H,10Hspiro[anthracene-9,1'-isobenzofuran]-3,6-diyl diacetate (6). In a $25 \mathrm{~mL}$ roundbottom flask equipped with a stir bar under $\mathrm{N}_{2}$ atmosphere, Compound 5 ( $0.119 \mathrm{mmol}, 58 \mathrm{mg}, 1.0$ equiv) was dissolved in $8 \mathrm{~mL}$ DCM. The reaction was cooled to $0{ }^{\circ} \mathrm{C}$. DIPEA $(0.155 \mathrm{mmol}, 27 \mu \mathrm{L}, 1.3$ equiv) and $N, N, N^{\prime}, N^{\prime}$-Tetramethyl- $O$-(1H-benzotriazol-1-yl) uronium hexafluorophosphate (HBTU) (0.142 mmol, $54 \mathrm{mg}, 1.2$ equiv) were then added and stirred for $10 \mathrm{~min}$, upon which the HBTU activated ester was visible by TLC. tert-Butyl piperazine-1-carboxylate $(0.143 \mathrm{mmol}, 27 \mathrm{mg}, 1.2$ equiv) was then added, and the reaction was allowed to stir overnight. Upon completion, the reaction was washed in brine/ $\mathrm{NH}_{4} \mathrm{Cl}$, eluted with 2 x $20 \mathrm{~mL} \mathrm{DCM}$, dried with $\mathrm{Na}_{2} \mathrm{SO}_{4}$, filtered, and concentrated under reduced pressure. Column chromatography (50-75\% EtOAc/Hexanes) yielded Compound 6 (0.10 mmol, $66 \mathrm{mg}, 85 \%)$ as a white foam. ${ }^{1} \mathrm{H}$ NMR $\left(500 \mathrm{MHz}, \mathrm{CDCl}_{3}\right) \delta 8.01$ (d, $1 \mathrm{H}, J=8.0 \mathrm{~Hz}), 7.56(\mathrm{~d}, 1 \mathrm{H}, J=8.0 \mathrm{~Hz}), 7.33(\mathrm{~s}, 2 \mathrm{H}), 7.02(\mathrm{~s}, 1 \mathrm{H}), 6.86(\mathrm{~d}, 2 \mathrm{H}, J=4.0 \mathrm{~Hz}), 6.73$ $(\mathrm{d}, 2 \mathrm{H}, J=4.0 \mathrm{~Hz}), 3.18-3.76(\mathrm{~m}, 8 \mathrm{H}), 2.25(\mathrm{~s}, 6 \mathrm{H}), 1.79(\mathrm{~s}, 3 \mathrm{H}), 1.78(\mathrm{~s}, 3 \mathrm{H}), 1.38(\mathrm{~s}, 9 \mathrm{H}) ;{ }^{13} \mathrm{C}$ 
NMR (125 MHz, $\left.\mathrm{CDCl}_{3}\right) \delta 169.11,168.5,155.1,154.4,151.6,146.7,142.0,129.1,128.2,122.7$, 120.8, 119.6, 85.5, 80.5, 69.3, 53.9, 38.6, 35.0, 32.6, 29.3, 28.4, 21.2; HRMS calcd for $\mathrm{C}_{37} \mathrm{H}_{38} \mathrm{~N}_{2} \mathrm{O}_{9}$ $[\mathrm{M}+\mathrm{Na}]^{+}$677.2470, found 677.2468.

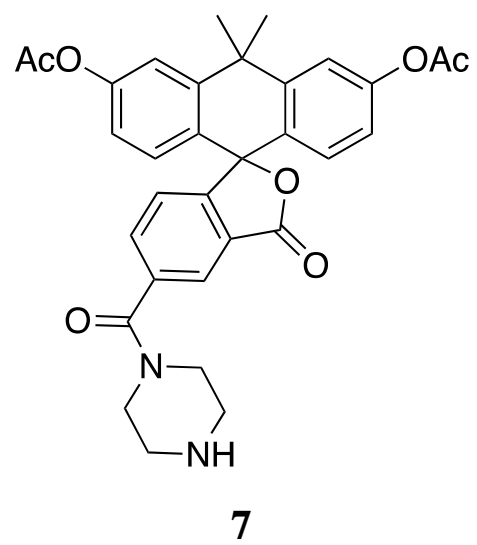

10,10-dimethyl-3'-oxo-5'-(piperazine-1-carbonyl)-3'H,10H-spiro[anthracene-9,1'-

isobenzofuran]-3,6-diyl diacetate (7). in a $20 \mathrm{~mL}$ vial, compound 6 was dissolved in $5 \mathrm{~mL}$ DCM. $1 \mathrm{~mL}$ TFA was added under $\mathrm{N}_{2}$ atmosphere at RT and stirred for $2 \mathrm{hr}$. Upon completion as monitored by TLC, $5 \mathrm{~mL}$ toluene was added, and the reaction contents were evaporated. The crude product was triturated $2 \mathrm{x}$ with $5 \mathrm{~mL} \mathrm{MeOH}$ to obtain compound 7 (0.098 mmol, $54 \mathrm{mg}, 98 \%)$ as a tan foam. ${ }^{1} \mathrm{H}$ NMR $\left(400 \mathrm{MHz}, \mathrm{CDCl}_{3}\right) \delta 8.04(\mathrm{~d}, 1 \mathrm{H}, J=7.2 \mathrm{~Hz}), 7.59(\mathrm{~d}, 1 \mathrm{H}, J=7.2 \mathrm{~Hz}), 7.38$ $(\mathrm{d}, 2 \mathrm{H}, J=1.6 \mathrm{~Hz}), 7.073(\mathrm{~s}, 1 \mathrm{H}), 6.90(\mathrm{dd}, 2 \mathrm{H}, J=8.8 \mathrm{~Hz}, J=1.6 \mathrm{~Hz}), 6.76(\mathrm{~d}, 2 \mathrm{H}, J=8.8 \mathrm{~Hz})$, 3.42-3.96 (m, 4H), 3.13 (bs, 4H), 2.29 (s, 6H), 1.84 (s, 3H) 1.75 (s, 3H); ${ }^{13} \mathrm{C}$ NMR (100 MHz, $\left.\mathrm{CDCl}_{3}\right) \delta 169.5,169.3,168.6,155.5,151.6,146.5,140.3,128.9,128.3,127.7,127.4,126.1,122.8$, 120.9, 119.7, 85.6, 43.3, 38.4, 34.7, 33.1, 21.1; HRMS calcd for $\mathrm{C}_{32} \mathrm{H}_{30} \mathrm{~N}_{2} \mathrm{O}_{7}[\mathrm{M}+\mathrm{Na}]^{+}$577.1945, found 577.1927 .

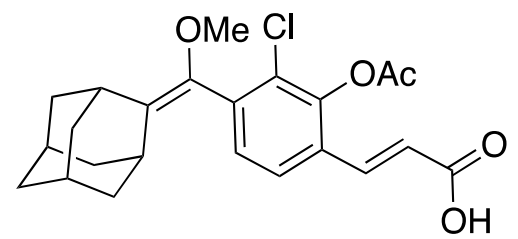

8

(E)-3-(2-acetoxy-4-(((1r,3r,5R,7S)-adamantan-2-ylidene)(methoxy)methyl)-3-

chlorophenyl)acrylic acid (8). Compound $\mathbf{S 3}^{4}(0.368 \mathrm{mmol}, 138 \mathrm{mg}, 1.0$ equiv) was dissolved in 
$5 \mathrm{~mL}$ acetic anhydride in a $20 \mathrm{~mL}$ roundbottom flask equipped with a stir bar. Pyridine $(1.84 \mathrm{mmol}$, $0.148 \mathrm{~mL}, 5.0$ equiv) was added. The reaction was heated to $80^{\circ} \mathrm{C}$ and stirred for $30 \mathrm{~min}$ until TLC showed disappearance of starting material, and appearance of two spots, indicating a mixture of the generated acrylic anhydride and free acid. The crude mixture was washed in $1 \mathrm{M} \mathrm{HCl}$, eluted with 2x $10 \mathrm{~mL}$ DCM, dried with $\mathrm{Na}_{2} \mathrm{SO}_{4}$, and concentrated under reduced pressure. The crude was then dissolved in $10 \mathrm{~mL} \mathrm{1:1} \mathrm{THF} \mathrm{H}_{2} \mathrm{O}$ mixture. Pyridine ( $1.84 \mathrm{mmol}, 0.148 \mathrm{~mL}, 5.0$ equiv) and $\mathrm{Et}_{3} \mathrm{~N}\left(0.368 \mathrm{mmol}, 51 \mu \mathrm{L}, 1.0\right.$ equiv). was added. The reaction was heated to $80^{\circ} \mathrm{C}$ and stirred for 20 min, at which point TLC showed disappearance of the mixed anhydride. Column chromatography in 50\% EtOAc/Hexanes and 1\% AcOH yielded $8(116 \mathrm{mg}, 76 \%)$ as a yellow foam. ${ }^{1} \mathrm{H}$ NMR (400 MHz, $\left.\mathrm{CDCl}_{3}\right) \delta 10.58$ (bs, $\left.1 \mathrm{H}\right), 7.74(\mathrm{~d}, 1 \mathrm{H}, J=16.0 \mathrm{~Hz}), 7.57$ (d, 1H, $J=$ $8.0 \mathrm{~Hz}), 7.24(\mathrm{~d}, 1 \mathrm{H}, J=8.0 \mathrm{~Hz}), 6.49(\mathrm{~d}, 1 \mathrm{H}, J=16.0 \mathrm{~Hz}), 3.34(\mathrm{~s}, 3 \mathrm{H}), 3.30(\mathrm{~s}, 1 \mathrm{H}), 2.47(\mathrm{~s}, 3 \mathrm{H})$ $1.61-2.13(\mathrm{~m}, 12 \mathrm{H}) ;{ }^{13} \mathrm{C}$ NMR $\left(100 \mathrm{MHz}, \mathrm{CDCl}_{3}\right) \delta 171.4,168.1,146.4,139.5,138.9,138.3$, 133.3, 129.5, 129.1, 128.5, 125.1, 120.6, 60.5, 57.4, 39.2, 39.0, 38.6, 37.0, 32.9, 29.8, 28.3, 28.3, 20.6, 20.6, 20.5, 14.9; HRMS calcd for $\mathrm{C}_{23} \mathrm{H}_{25} \mathrm{ClO}_{5}[\mathrm{M}+\mathrm{Na}]^{+} 439.1283$, found 439.1287.

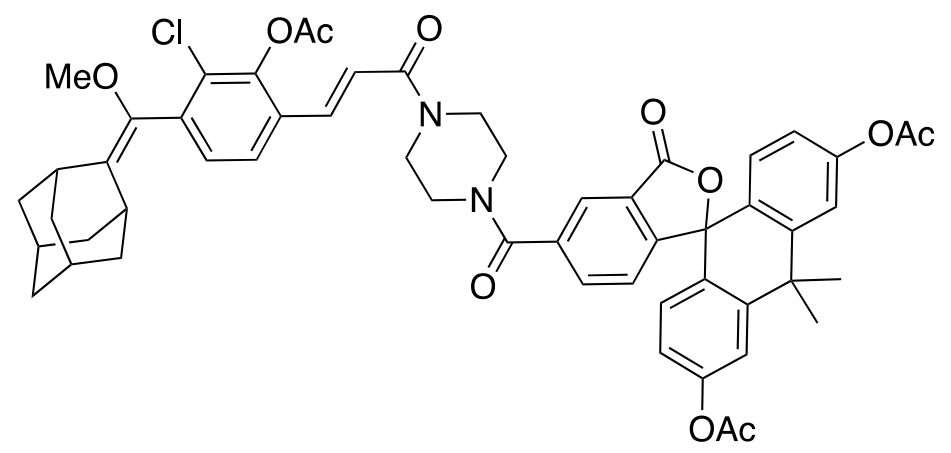

9

5'-(4-((E)-3-(2-acetoxy-4-(((1r,3r,5R,7S)-adamantan-2-ylidene)(methoxy)methyl)-3chlorophenyl)acryloyl)piperazine-1-carbonyl)-10,10-dimethyl-3'-oxo-3'H,10Hspiro[anthracene-9,1'-isobenzofuran]-3,6-diyl diacetate (9). In a $25 \mathrm{~mL}$ roundbottom flask equipped with a stir bar under $\mathrm{N}_{2}$ atmosphere, Compound $8(0.055 \mathrm{mmol}, 23 \mathrm{mg}, 1.0$ equiv) was dissolved in $2 \mathrm{~mL}$ DCM. The reaction was cooled to $0^{\circ} \mathrm{C}$. DIPEA ( $0.072 \mathrm{mmol}, 13 \mu \mathrm{L}, 1.3$ equiv) and HBTU ( $0.142 \mathrm{mmol}, 54 \mathrm{mg}, 1.2$ equiv) were then added and stirred for $10 \mathrm{~min}$, upon which the HBTU activated ester was visible by TLC. Compound 7 ( $0.055 \mathrm{mmol}, 30 \mathrm{mg}, 1.0$ equiv) was then added, and the reaction was allowed to stir overnight. Upon completion, the reaction was 
washed in brine/ $\mathrm{NH}_{4} \mathrm{Cl}$, eluted with $2 \times 20 \mathrm{~mL}$ DCM, dried with $\mathrm{Na}_{2} \mathrm{SO}$, filtered, and concentrated under reduced pressure. Column chromatography (75-100\% EtOAc/Hexanes) yielded Compound $9(0.10 \mathrm{mmol}, 8 \mathrm{mg}, 85 \%)$ as a white solid. ${ }^{1} \mathrm{H}$ NMR $\left(400 \mathrm{MHz}, \mathrm{CDCl}_{3}\right) \delta 8.10(\mathrm{~d}, 1 \mathrm{H}, J=7.6 \mathrm{~Hz})$ $7.65(\mathrm{~m}, 2 \mathrm{H}), 7.53(\mathrm{~d}, 1 \mathrm{H}, 8.0 \mathrm{~Hz}), 7.38(\mathrm{~s}, 1 \mathrm{H}), 7.18(\mathrm{~d}, 1 \mathrm{H}, J=8.0 \mathrm{~Hz}), 6.79-6.94(\mathrm{~m}, 6 \mathrm{H})$, 4.52-4.85 (m, 6H) 3.25-3.36 (m, 6H), $2.41(\mathrm{~s}, 3 \mathrm{H}), 2.31(\mathrm{~s}, 6 \mathrm{H}), 1.61-2.16(\mathrm{~m}, 12 \mathrm{H}) ;{ }^{13} \mathrm{C}$ NMR $\left(100 \mathrm{MHz}, \mathrm{CDCl}_{3}\right) \delta 169.1,168.5,168.2,164.9,151.5,146.1,141.5,139.0,137.5,136.4,133.0$, 129.3, 129.0, 128.6, 128.1, 126.1, 124.5, 120.8, 119.6, 60.4, 57.3, 56.0, 39.22, 38.5, 37.0, 34.9, 32.9, 29.7, 28.3, 28.1, 21.2, 21.1, 20.6, 14.2; HRMS calcd for $\mathrm{C}_{55} \mathrm{H}_{53} \mathrm{ClN}_{2} \mathrm{O}_{11}[\mathrm{M}+\mathrm{H}]^{+}$953.3411, found 953.3459 .

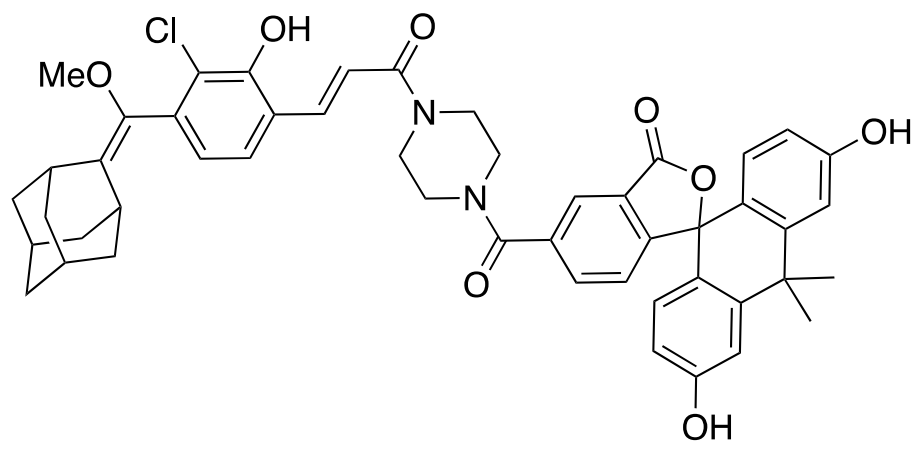

10

5'-(4-((E)-3-(4-(((1r,3r,5R,7S)-adamantan-2-ylidene)(methoxy)methyl)-3-chloro-2hydroxyphenyl)acryloyl)piperazine-1-carbonyl)-3,6-dihydroxy-10,10-dimethyl-3'H,10Hspiro[anthracene-9,1'-isobenzofuran]-3'-one (10). In a 20-dram vial, compound 9 (0.021 mmol, $20 \mathrm{mg}$ ) was dissolved in $2 \mathrm{~mL}$ THF, and $2 \mathrm{~mL} 10 \mathrm{M} \mathrm{LiOH}$ was added under $\mathrm{N}_{2}$ atmosphere at RT. The reaction was stirred for $2.5 \mathrm{hr}$. upon completion as determined by TLC, the reaction was washed in brine, and $30 \mathrm{~mL} 1 \mathrm{M} \mathrm{HCL}$ was then added. The organic layer was eluted with 2x 10 mL EtOAc, then 2x $10 \mathrm{~mL}$ DCM, dried with $\mathrm{Na}_{2} \mathrm{SO}_{4}$, filtered, and concentrated under reduced pressure, yielding $10(18 \mathrm{mg}, 0.021 \mathrm{mmol}$, quantitative $)$ as a red solid without further purification. ${ }^{1} \mathrm{H}$ NMR (400 MHz, Acetone-d6) $\delta 8.06(\mathrm{~d}, 1 \mathrm{H}, J=7.6 \mathrm{~Hz}), 7.96(\mathrm{~d}, 1 \mathrm{H}, J=15.6 \mathrm{~Hz}), 7.21(\mathrm{~m}$, $1 \mathrm{H}), 6.86(\mathrm{~d}, 4 \mathrm{H}, J=8.0 \mathrm{~Hz}), 6.72(\mathrm{~d}, 1 \mathrm{H}, J=2.0 \mathrm{~Hz}) 6.70(\mathrm{~d}, 2 \mathrm{H}, J=2.0 \mathrm{~Hz}), 6.63(\mathrm{~d}, 1 \mathrm{H}, J=$ $8.8 \mathrm{~Hz}$ ), 3.50-3.92 (m, 6H), $3.28(\mathrm{~s}, 6 \mathrm{H}), 2.65-3.15(\mathrm{~m}, 12 \mathrm{H}) ;{ }^{13} \mathrm{C} \mathrm{NMR}\left(100 \mathrm{MHz}, \mathrm{CDCl}_{3}\right) \delta$ 171.2, 169.0, 168.1, 165.1, 158.2, 155.5, 151.4, 147.4, 140.3, 136.5, 136.2, 130.3, 129.2, 128.2, 125.7, 125.2, 125.0, 124.0, 123.1, 122.8, 122.5, 119.8, 118.9, 114.8, 112.7, 86.6, 56.1, 38.7, 38.5, 
38.1, 37.9, 36.8, 34,6, 32.9, 19.6; HRMS calcd for $\mathrm{C}_{49} \mathrm{H}_{47} \mathrm{ClN}_{2} \mathrm{O}_{8}[\mathrm{M}+\mathrm{H}]^{+}$827.3094, found 827.3089.

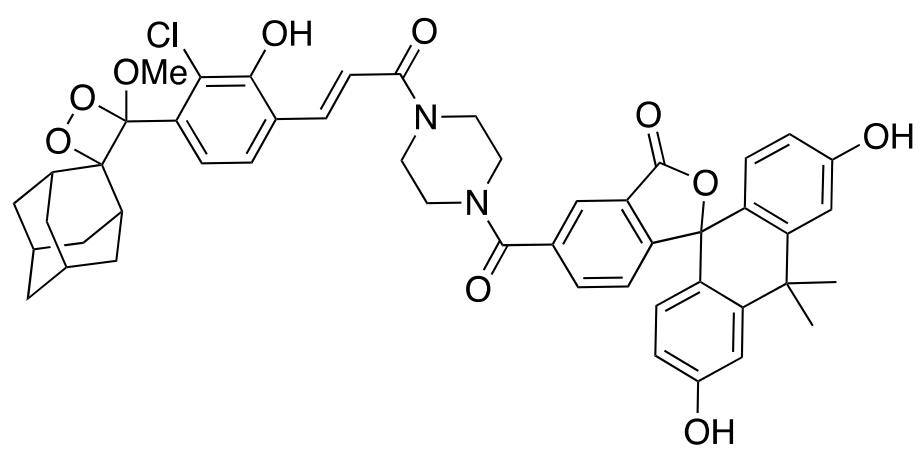

Ratio-pHCL-1

5'-(4-((E)-3-(3-chloro-2-hydroxy-4-((1r,3r,5r,7r)-4'-methoxyspiro[adamantane-2,3'[1,2]dioxetan]-4'-yl)phenyl)acryloyl)piperazine-1-carbonyl)-3,6-dihydroxy-10,10-dimethyl3'H,10H-spiro[anthracene-9,1'-isobenzofuran]-3'-one (Ratio-pHCL-1). In a 2-neck roundbottom flask, compound $10(0.021 \mathrm{mmol})$, was dissolved in $2 \mathrm{~mL}$ THF at $0{ }^{\circ} \mathrm{C} .2 \mathrm{mg}$ methylene blue was added. The reaction was irradiated under yellow light for $1 \mathrm{hr}$ and monitored by LRMS. Upon completion, the crude was evaporated onto silica gel and loaded for column chromatography in 5\% MeOH/DCM, yielding Ratio-pHCL-1 (16 mg, 90\%) as a white solid. ${ }^{1} \mathrm{H}$ NMR (400 MHz, Acetone-d6) $\delta 8.06(\mathrm{~d}, 1 \mathrm{H}, J=8.0 \mathrm{~Hz}), 7.94(\mathrm{~d}, 1 \mathrm{H}, J=16.0 \mathrm{~Hz}), 7.76(\mathrm{dd}, 1 \mathrm{H}$, $J=8.0 \mathrm{~Hz}, J=1.2 \mathrm{~Hz}$ ), $5.64(\mathrm{~d}, 1 \mathrm{H}, J=7.6 \mathrm{~Hz}), 7.35(\mathrm{bs}, 1 \mathrm{H}), 7.20$ (m, 4H) 6.70 (dd, 2H, $J=8.8$ $\mathrm{Hz}, J=2.4 \mathrm{~Hz}$ ), 3.50-4.00 (m, 4H), 3.19, (s, 3H), 2.96 (s, 1H), 2.75 (s, 4H), 2.062 (s, 3H), 2.71 (s, 3H) ${ }^{13} \mathrm{C}$ NMR (100 MHz, Acetone-d6) $\delta$ 168.9, 168.1, 164.8, 158.1, 155.5, 152.6, 150.5, 147.3, $142.7,140.5,136.5,136.9,133.2,129.3,128.2,127.5,125.8,125.0,123.9,122.8,122.5,120.2$, 114.7, 112.6, 112.0, 111.5, 95.5, 86.5, 67.17, 48.8, 38.1, 37.8, 36.3, 34.6, 33.5, 32.4, 31.9, 26.2, 25.9, 25.3; HRMS calcd for $\mathrm{C}_{49} \mathrm{H}_{47} \mathrm{ClN}_{2} \mathrm{O}_{10}[\mathrm{M}+\mathrm{H}]^{+}$859.2992, found 859.3017.

\section{Ratio-pHCL-1 in vitro characterization}

Calibration of Ratio-pHCL-1. Chemiluminescent emission spectra were acquired using a Hitachi F-7000 fluorescence spectrophotometer via the luminescence detection module and scanning luminescence emission from 400-900 $\mathrm{nm}$ in response to exposure of Ratio-pHCL-1 to pH buffered solutions. Ratio-pHCL-1 in DMSO was added to a solution of $100 \mathrm{mM}$ Tris, PBS or 
carbonate buffers ranging from $\mathrm{pH}$ 6.81-10.02. For concentration dependence, 10, 20, and $40 \mu \mathrm{M}$ Ratio-pHCL-1 in 5\% DMSO were subjected to $100 \mathrm{mM}$ PBS buffered to pH 6.81, 7.45, and 8.02. For time dependence, $20 \mu \mathrm{M}$ Ratio-pHCL-1 in 5\% DMSO was subjected to $100 \mathrm{mM}$ PBS buffered to $\mathrm{pH} 6.81,7.45$, and 8.02, and the chemiluminescence emission spectra was measured at $\mathrm{t}=0,10,20$ and $30 \mathrm{~min}$. For DMSO dependence, $20 \mu \mathrm{M}$ Ratio-pHCL-1 in a final concentration of 1,5 , or $10 \%$ DMSO was subjected to $100 \mathrm{mM}$ PBS buffered to $\mathrm{pH} 6.81,7.45$, or 8.02. Each experiment was independently conducted 3 times, and analysis of each experiment was conducted by dividing emission intensity values at $580 \mathrm{~nm}$ over emission intensity values at $530 \mathrm{~nm}$ from the emission plot.

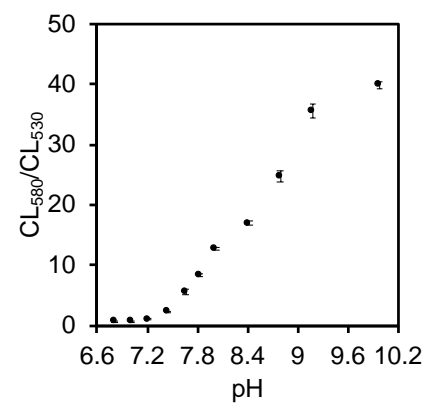

Figure S1. Ratio of chemiluminescence emission intensities at $580 \mathrm{~nm}$ and $530 \mathrm{~nm}$ of $20 \mu \mathrm{M}$ Ratio-pHCL-1 and 5\% DMSO in aqueous buffer $(\mathrm{pH}=6.81-10.02)$. All measurements were taken in $100 \mathrm{mM}$ PBS, $100 \mathrm{mM}$ Tris, or $100 \mathrm{mM}$ carbonate buffer, and measurements were taken $20 \mathrm{~s}$ after mixing. Error bars are $\pm \mathrm{SD}$ from $\mathrm{n}=3$ independent experiments.

Ratio-pHCL-1 kinetics. Kinetics data were acquired using a Biotek Cytation $5^{\circledR}$ plate reader using the luminescence detection mode, end point read type. The temperature was set at $37{ }^{\circ} \mathrm{C}$ under ambient atmosphere. The gain was set at 135 and the read height was set at $4.5 \mathrm{~mm}$. In a 96-well plate, $1.0 \mu \mathrm{L}$ of $0.25 \mathrm{mM}$ Ratio-pHCL-1 was added to wells containing a solution of $237.5 \mu \mathrm{L}$ $100 \mathrm{mM}$ PBS $(\mathrm{pH}=7.45)$ and $11.5 \mu \mathrm{L}$ DMSO to create a final concentration of $1.0 \mu \mathrm{M}, 5 \%$ DMSO. The plate was then immediately placed into the plate reader and allowed to stir for $1 \mathrm{~min}$. Luminescence data was acquired every 2 min for $4 \mathrm{hr}$. 


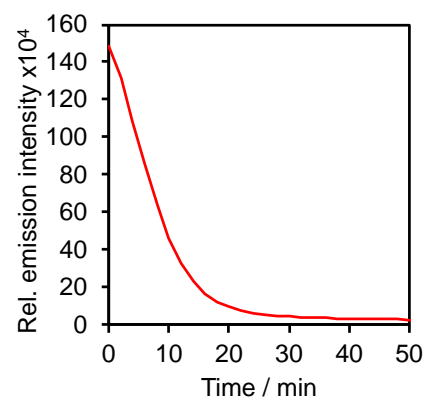

Figure S2. Kinetic emission plot of $1.0 \mu \mathrm{M}$ Ratio-pHCL-1 in $100 \mathrm{mM}$ PBS, pH 7.44, 5\% DMSO, $37^{\circ} \mathrm{C}$.

3. Cell culture and biological studies. Human lung adenocarcinoma epithelial cells (A549) cells were purchased from ATCC and cultured in Ham's F-12K (Kaighn's) Medium supplemented with 10\% Fetal Bovine Serum (FBS) and 1\% antibiotics (penicillin/streptomycin, $100 \mathrm{U} / \mathrm{mL}$ ). Cells were maintained in a humidified incubator at $37{ }^{\circ} \mathrm{C}$ with $5 \% \mathrm{CO}_{2}$. One or two days before the experiment, cells were passaged and plated on Costar® 12 -well plates by adding $150 \mathrm{~K}-200 \mathrm{~K}$ of cells per well, filling each well up to $1 \mathrm{~mL}$ of media.

Ratio-pHCL-1 cell penetration A549 cells were seeded in a 12 well plate, and maintained at 37 ${ }^{\circ} \mathrm{C}$ with $5 \% \mathrm{CO}_{2}$, and monitored until the plate reached $80 \%$ confluency. The cells were then washed with 1x PBS, and $996 \mu \mathrm{L}$ complete F12k was added. Next, $4.0 \mu \mathrm{L}$ of $5 \mathrm{mM}$ Ratio-pHCL1 in DMSO was added to obtain a final concentration of $20 \mu \mathrm{M}$ Ratio-pHCL-1 incubated for $\mathrm{t}=$ 80 min. Upon completion of incubation, cells were washed twice with 1x PBS and reconstituted with $1000 \mu \mathrm{L}$ incomplete F12K, or were given no wash, and the plate was imaged with an EVOS microscope, and images were taken using GFP and RFP filters with the 20x objective. Images taken with the GFP filter were uniformly processed using Image $\mathrm{J}$ with contrast changed to min $=$ 18 , $\max =112$, and RFP images were uniformly processed using Image $\mathrm{J}$ with contrast changed to $\min =66, \max =135$. 


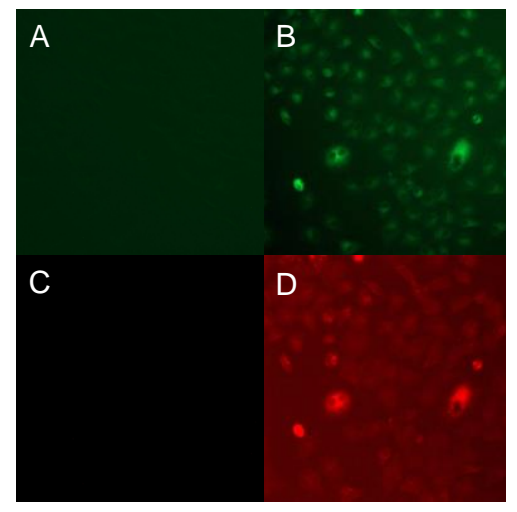

Figure S3. (A-B) Fluorescence microscopy images using a GFP filter set of A549 cells with (A) no probe and (B) $20 \mu \mathrm{M}$ Ratio-pHCL-1 incubated in cells for $80 \mathrm{~min}$, followed by wash step. (C-D) Fluorescence microscopy images using a RFP filter set of A549 cells with (A) no probe and (B) $20 \mu$ M Ratio-pHCL-1 1 incubated in cells for $80 \mathrm{~min}$, followed by wash step.

4. Ratiometric pH imaging. Chemiluminescent images were acquired with an IVIS Spectrum (Caliper, Waltham, MA) using the "Luminescent" and "Photograph" mode. For in vitro 96 well plate measurements, the exposure time was set as 0.5 seconds, binning was set to medium, F/stop was set as 4, FOV was set as C (12.9 cm), Excitation was blocked and the sequence was set for the emission mode, and images were acquired sequentially first using a $580 \mathrm{~nm}$ bandpass filter, then a $540 \mathrm{~nm}$ bandpass filter. A final concentration of $1 \mu \mathrm{M}$ Ratio-pHCL-1 was added in a snake-like fashion (left to right across $\mathrm{pH}$ gradient, then down one row, right to left across $\mathrm{pH}$ gradient, etc.) to $100 \mathrm{mM}$ buffer ranging from $\mathrm{pH}$ 6.81-8.42. Image analysis was carried out by setting individual ROI's to each well for both 580 and $540 \mathrm{~nm}$ filter images. The ROI's were then measured, which gave a total flux $(\mathrm{p} / \mathrm{s})$ for each ROI, the flux value at $580 \mathrm{~nm}$ was divided by the flux at $540 \mathrm{~nm}$ for each well.

In vitro pH measurement through tissue surrogate. For measurements through tissue surrogate (bologna, Kroger, Dallas, TX), the exposure time was set as 10.0 seconds, binning was set to medium, F/stop was set to 1, FOV was set to $\mathrm{C}(12.9 \mathrm{~cm})$, Excitation was blocked and the sequence was set for the emission mode. Images were acquired sequentially first using a $580 \mathrm{~nm}$ bandpass filter, then a $540 \mathrm{~nm}$ bandpass filter. A final concentration of $20 \mu \mathrm{M}$ Ratio-pHCL-1 was added in a snake-like fashion (left to right across $\mathrm{pH}$ gradient, then down one row, right to left across $\mathrm{pH}$ gradient, etc.) to $100 \mathrm{mM}$ buffer ranging from $\mathrm{pH}$ 6.81-8.42. Then, 1 slice of bologna measuring $2.8 \mathrm{~mm}$ thickness (Oscar Meyer) was placed on top of the 96-well plate, and luminescence was 
measured through the meat sample. All images were analyzed using Living Image software. Image analysis was carried out by setting individual ROI's to each well for both 580 and $540 \mathrm{~nm}$ filter images. The ROI's were then measured, which gave a total flux ( $\mathrm{p} / \mathrm{s})$ for each ROI, the flux value at $580 \mathrm{~nm}$ was divided by the flux at $540 \mathrm{~nm}$ for each well.
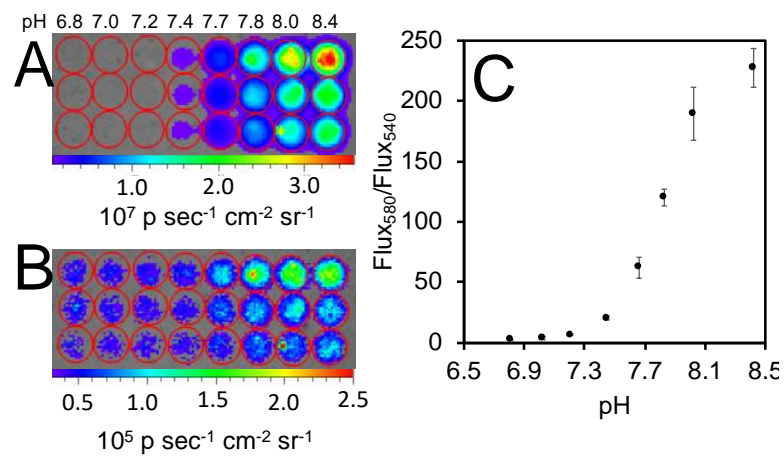

Figure S4. Chemiluminescence intensity images of the $\mathrm{pH}$ dependent emission of $20 \mu \mathrm{M}$ RatiopHCL-1 in $100 \mathrm{mM}$ PBS or Tris (pH 6.81-8.42) containing 5\% DMSO using (A) $580 \mathrm{~nm}$ bandpass filter or (B) $540 \mathrm{~nm}$ bandpass filter in an IVIS Spectrum with bologna slice $(2.8 \mathrm{~mm}$ thickness) covering 96 well plate. (C) Ratio of total flux (p/s) at $580 \mathrm{~nm}$ and $540 \mathrm{~nm} . \mathrm{n}=9$ technical replicates across 3 independent experiments, error bars are \pm SD.

Sacrificed mouse imaging. A solution of $950 \mu \mathrm{L}$ of 1.0 M PBS (pH 5.99-7.99) was injected into the peritoneal cavity of recently sacrificed CL6B57 mice aged 6-12 weeks old, then $50 \mu \mathrm{L}$ of 400 $\mu \mathrm{M}$ Ratio-pHCL-1 in DMSO was injected shortly after to achieve an approximate final concentration of $20 \mu \mathrm{M}$ Ratio-pHCL-1 with 5\% DMSO. The mice were imaged immediately after injection of the probe with a $580 \mathrm{~nm}$ and $540 \mathrm{~nm}$ filter with capture settings set to autoexposure and FOV set to $\mathrm{C}(12.9 \mathrm{~cm})$.

\section{Supplementary References}

(1) Kommreddy, A.; Bowsher, M. S.; Gunna, M. R.; Botha, K.; Vinod, T. K. Expedient Synthesis and Solvent Dependent Oxidation Behavior of a Water-Soluble IBX Derivative. Tetrahedron Lett. 2008, 49, 4378-4382.

(2) Grimm, J. B.; Sung, A. J.; Legant, W. R.; Hulamm, P.; Matlosz, S. M.; Betzig, E.; Lavis, L. D. Carbofluoresceins and Carborhodamines as Scaffolds for High-Contrast Fluorogenic Probes. ACS Chem. Biol. 2013, 8, 1303-1310. 
(3) Pastierik, T.; Šebej, P.; Medalová, J.; Štacko, P.; Klán, P. Near-Infrared Fluorescent 9Phenylethynylpyronin Analogues for Bioimaging. J. Org. Chem. 2014, 79, 3374-3382.

(4) Ryan, L. S.; Gerberich, J.; Cao, J.; An, W.; Jenkins, B. A.; Mason, R. P.; Lippert, A. R. Kinetics-Based Measurement of Hypoxia in Living Cells and Animals Using an Acetoxymethyl Ester Chemiluminescent Probe. ACS Sensors 2019, 4, 1391-1398.

\section{Reported Spectra}
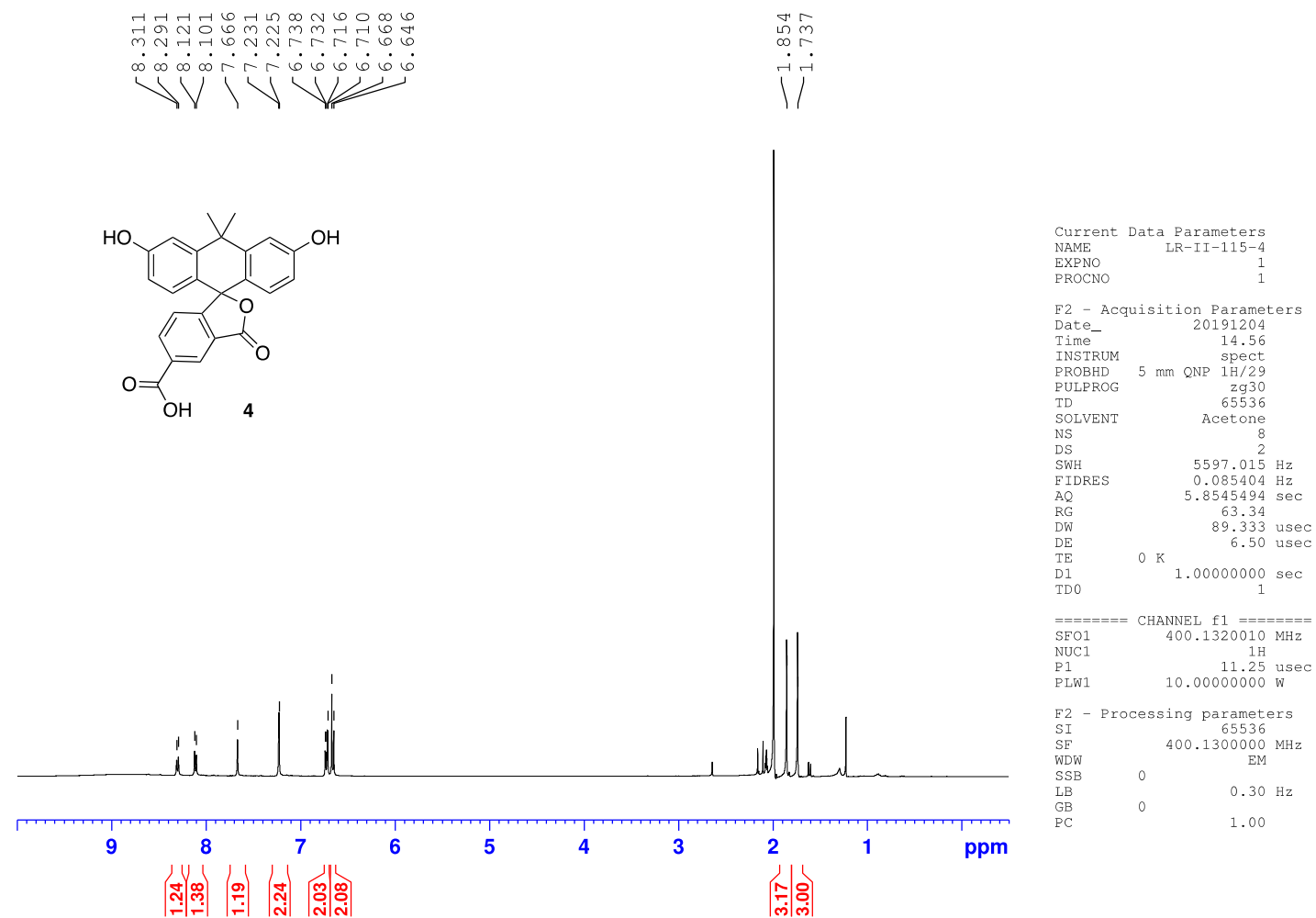

Figure S5. ${ }^{1} \mathrm{H}$ NMR spectrum (400 MHz, Acetone-D6) of 4. 

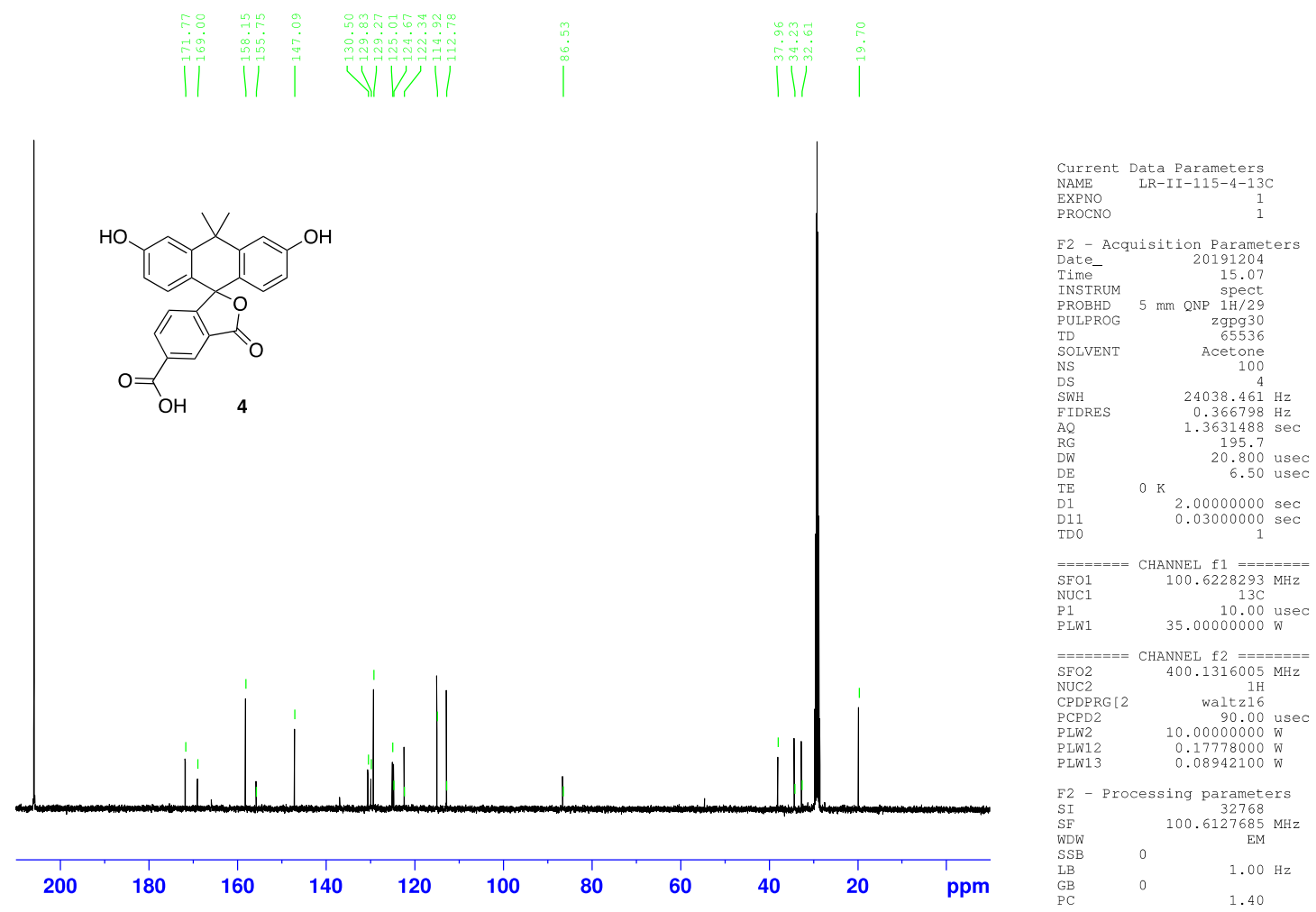

Figure S6. ${ }^{13} \mathrm{C}$ NMR spectrum (100 MHz, Acetone-D6) of 4. 

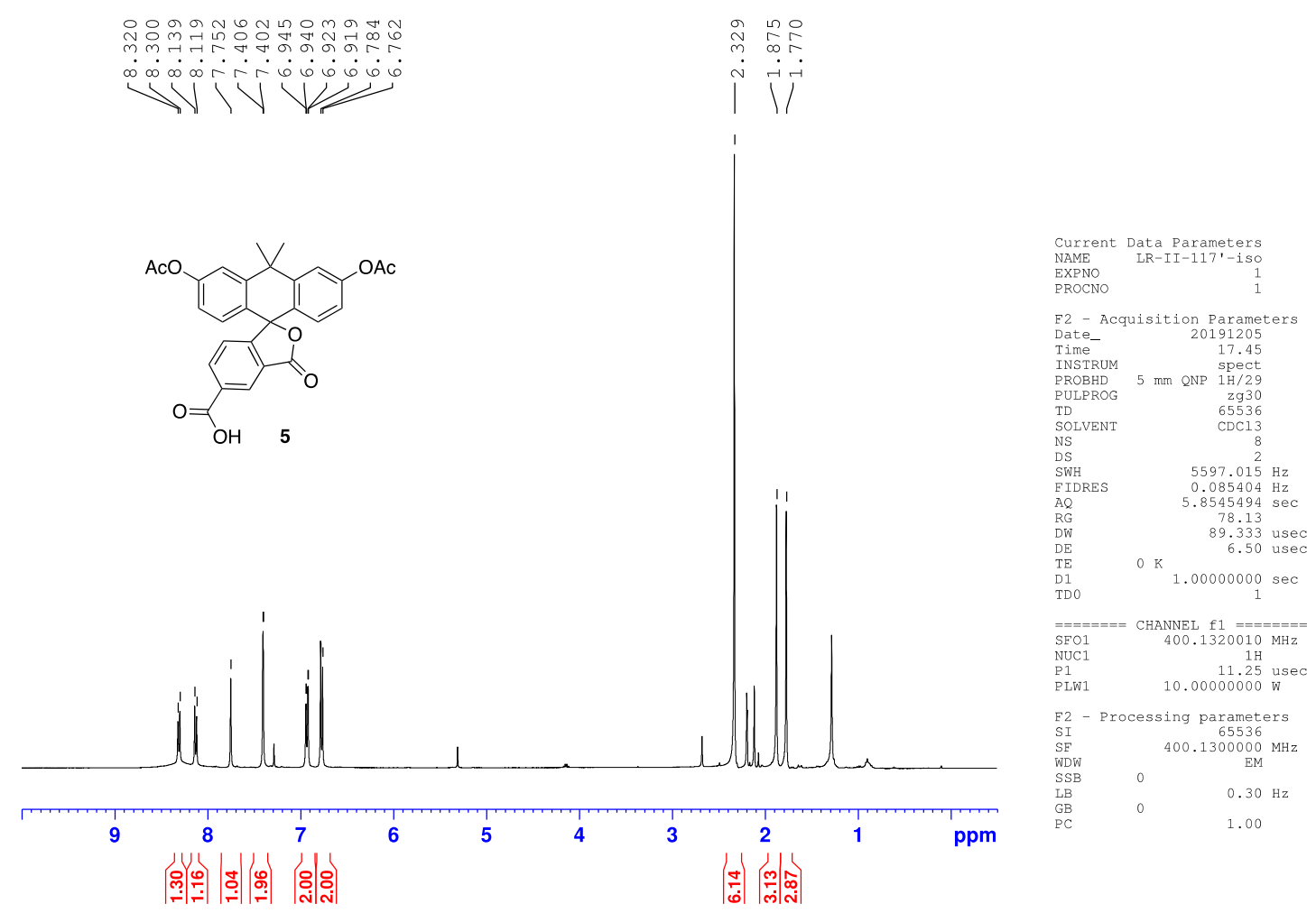
|

Figure S7. ${ }^{1} \mathrm{H}$ NMR spectrum $\left(400 \mathrm{MHz}, \mathrm{CDCl}_{3}\right)$ of $\mathbf{5}$ 

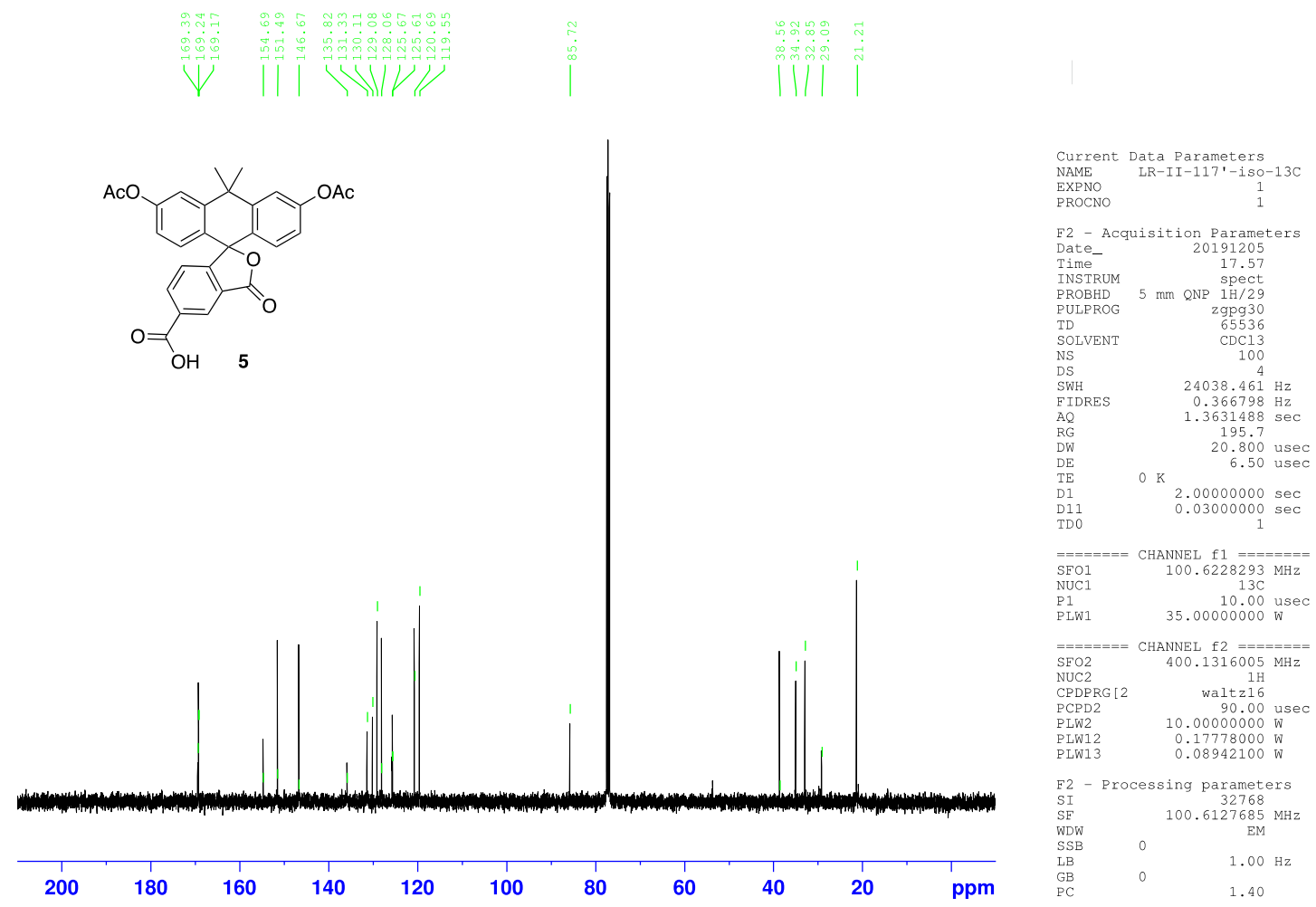

Figure S8. ${ }^{13} \mathrm{C}$ NMR spectrum $\left(100 \mathrm{MHz}, \mathrm{CDCl}_{3}\right)$ of 5 


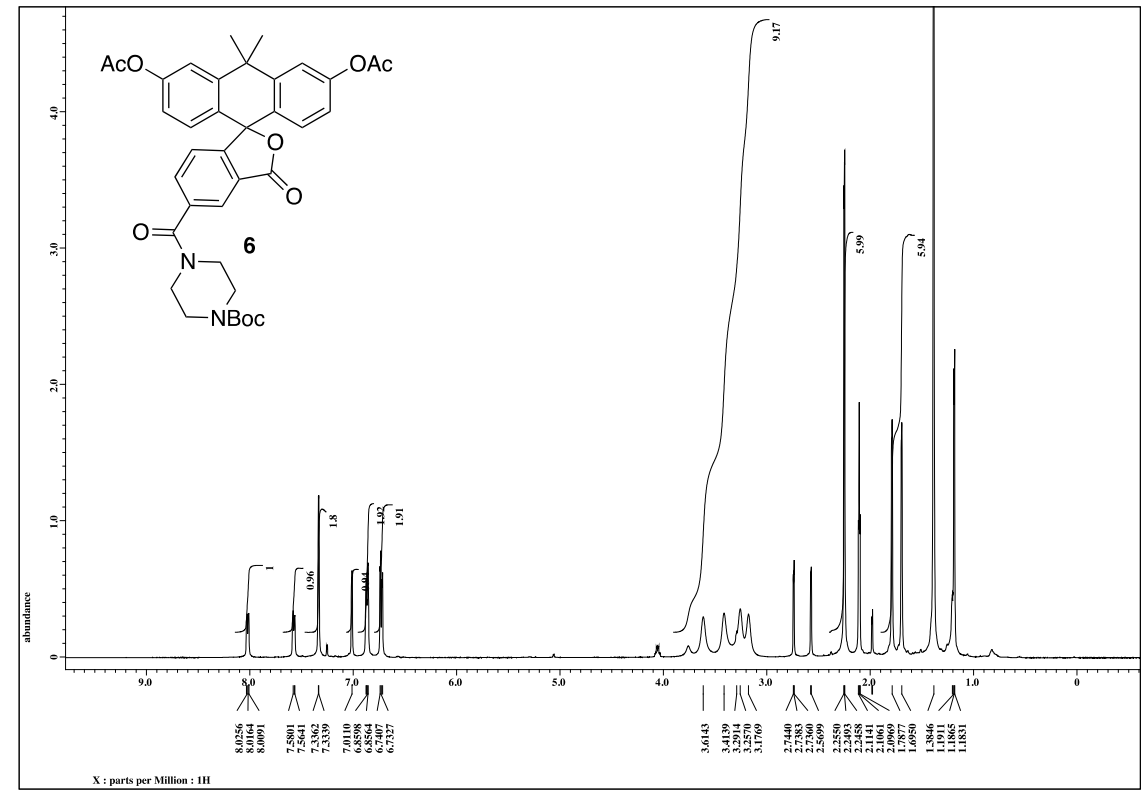

Figure S9. ${ }^{1} \mathrm{H} \mathrm{NMR}$ spectrum $\left(500 \mathrm{MHz}, \mathrm{CDCl}_{3}\right)$ of 6

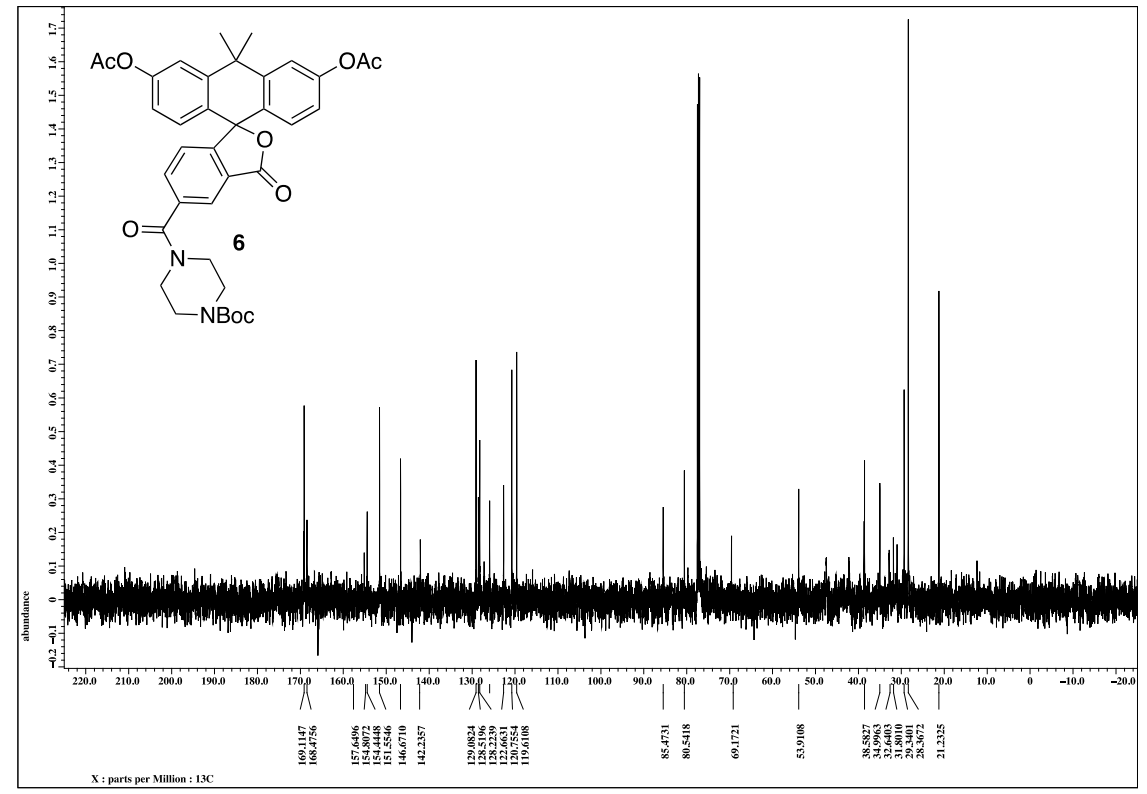

Figure S10. ${ }^{13} \mathrm{C}$ NMR spectrum $\left(125 \mathrm{MHz}, \mathrm{CDCl}_{3}\right)$ of $\mathbf{6}$. 

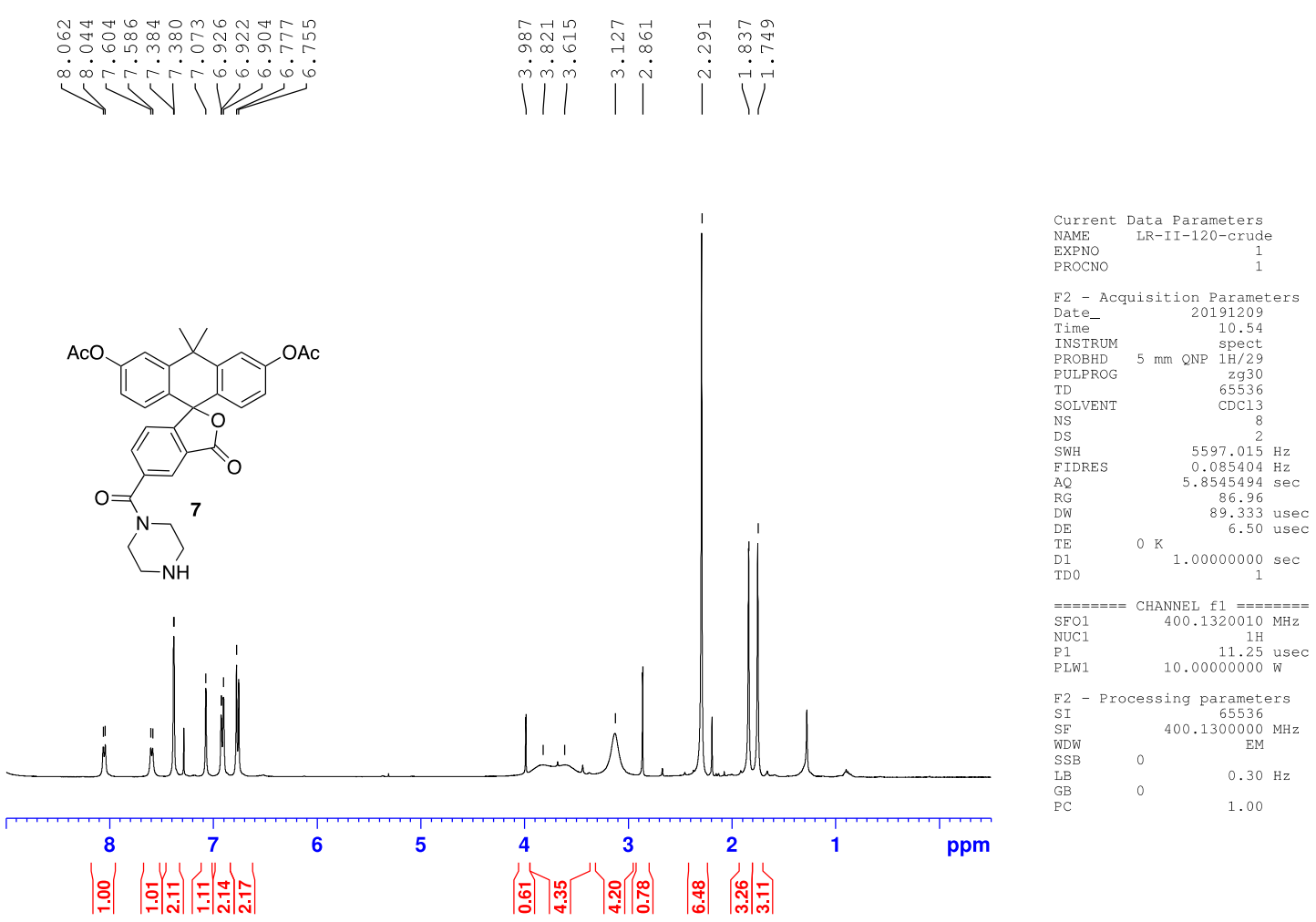

Figure S11. ${ }^{1} \mathrm{H}$ NMR spectrum $\left(400 \mathrm{MHz}, \mathrm{CDCl}_{3}\right)$ of 7 

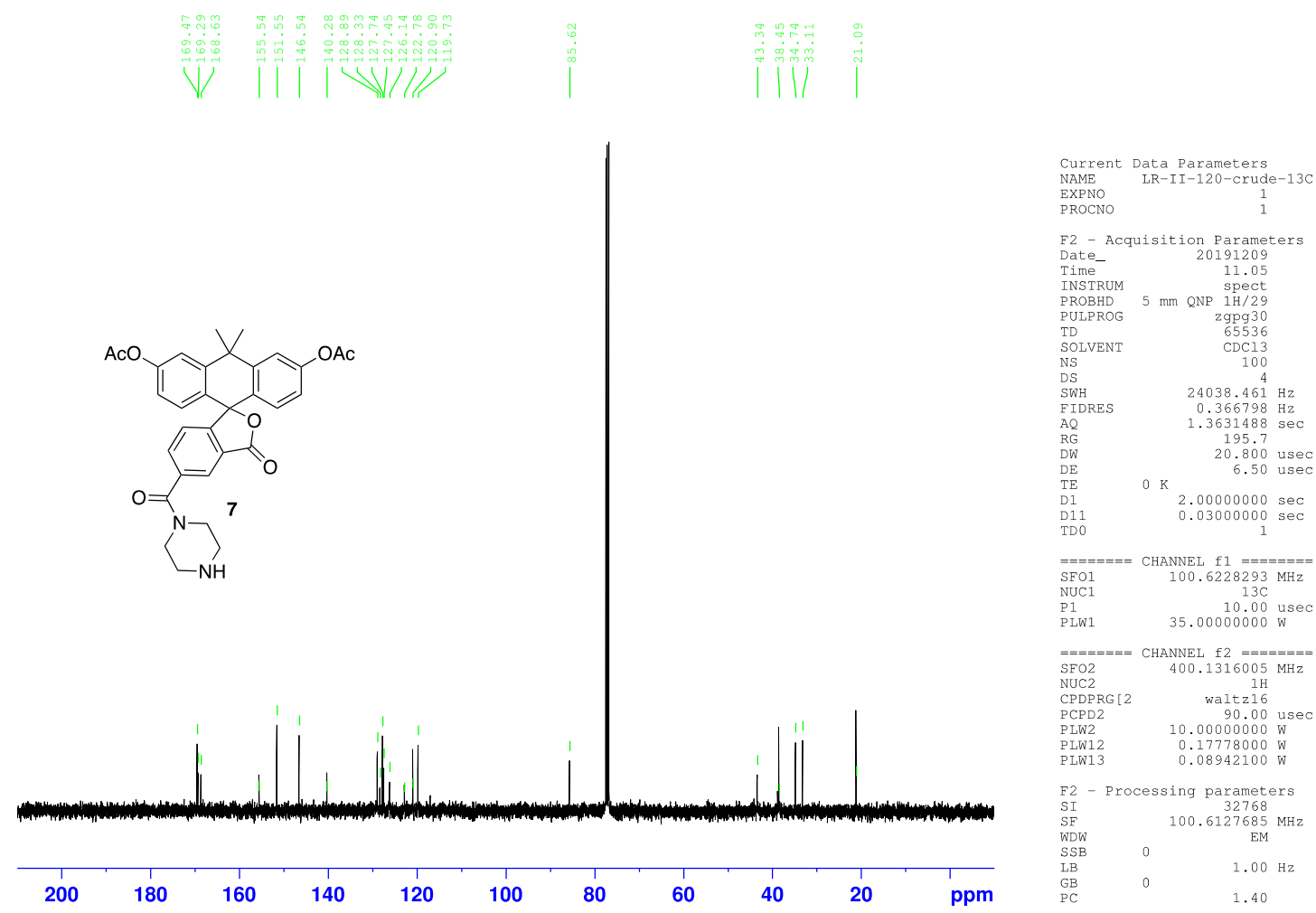

Figure S12. ${ }^{13} \mathrm{C}$ NMR spectrum $\left(100 \mathrm{MHz}, \mathrm{CDCl}_{3}\right)$ of 7. 


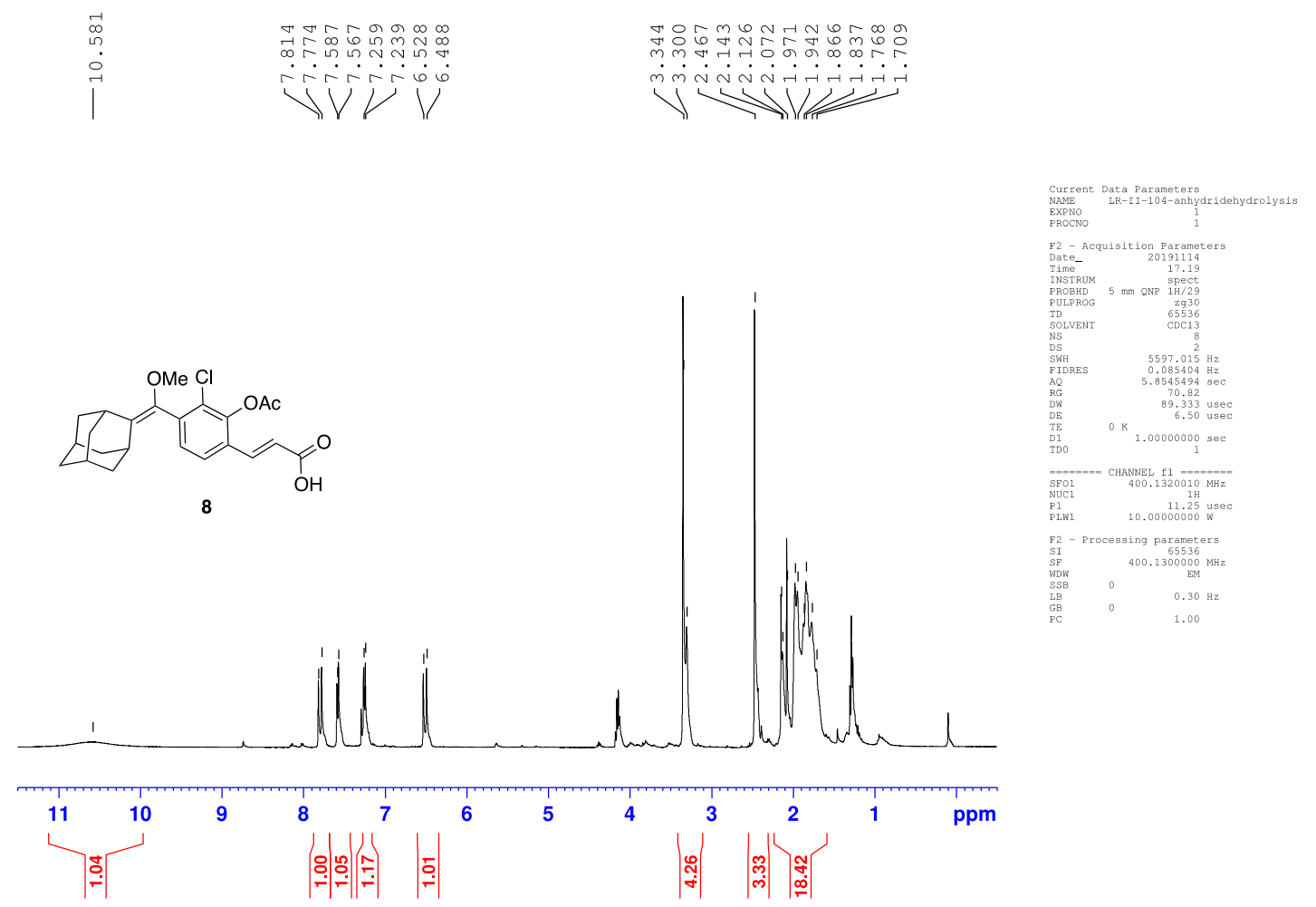

Figure S13. ${ }^{1} \mathrm{H}$ NMR spectrum $\left(400 \mathrm{MHz}, \mathrm{CDCl}_{3}\right)$ of 8. 


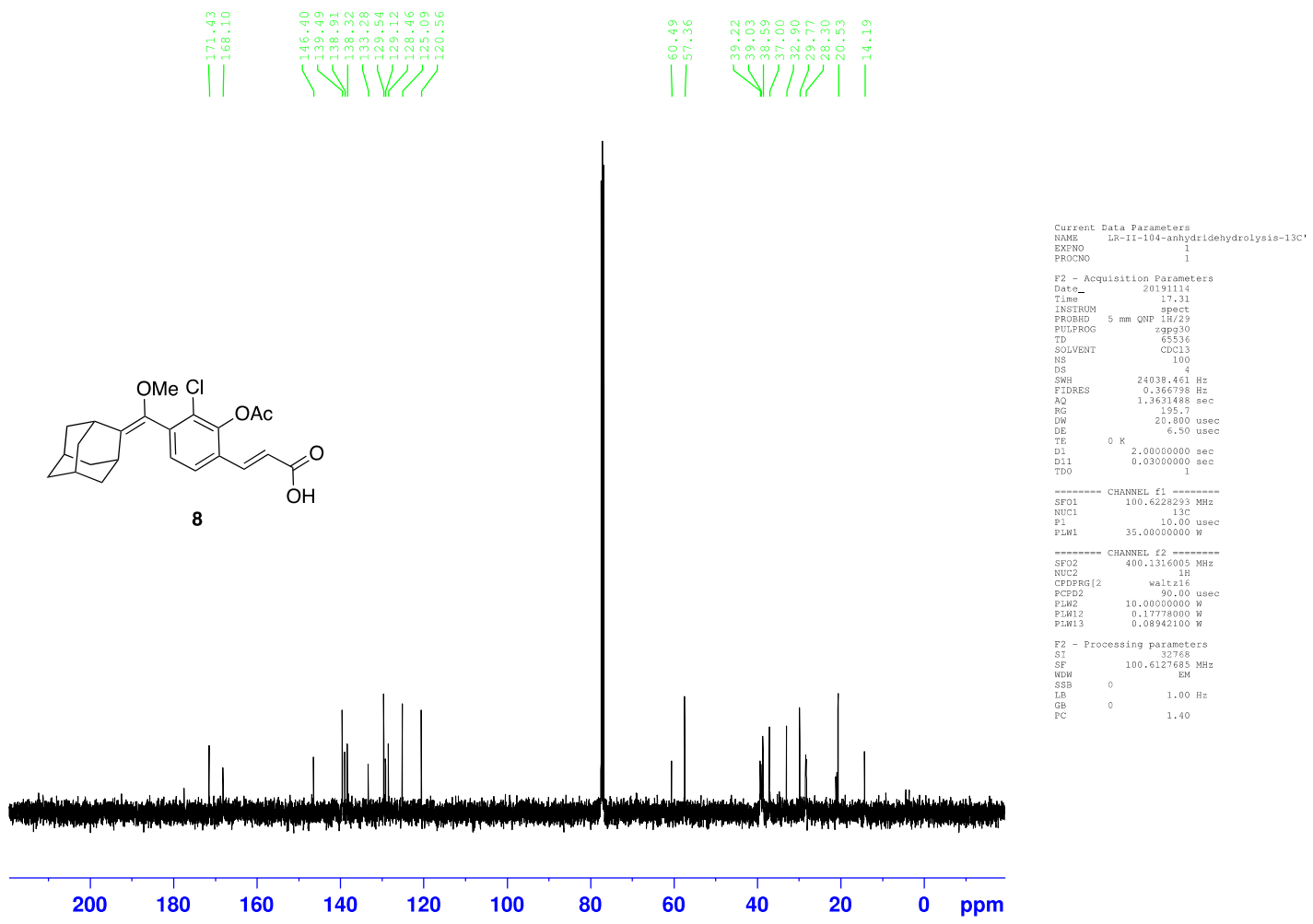

Figure S14. ${ }^{13} \mathrm{C}$ NMR $\left(100 \mathrm{MHz}, \mathrm{CDCl}_{3}\right)$ of 8 . 


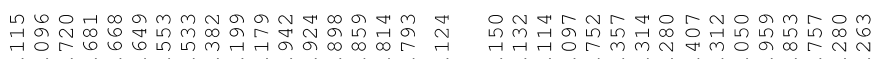

$\underbrace{\infty}$
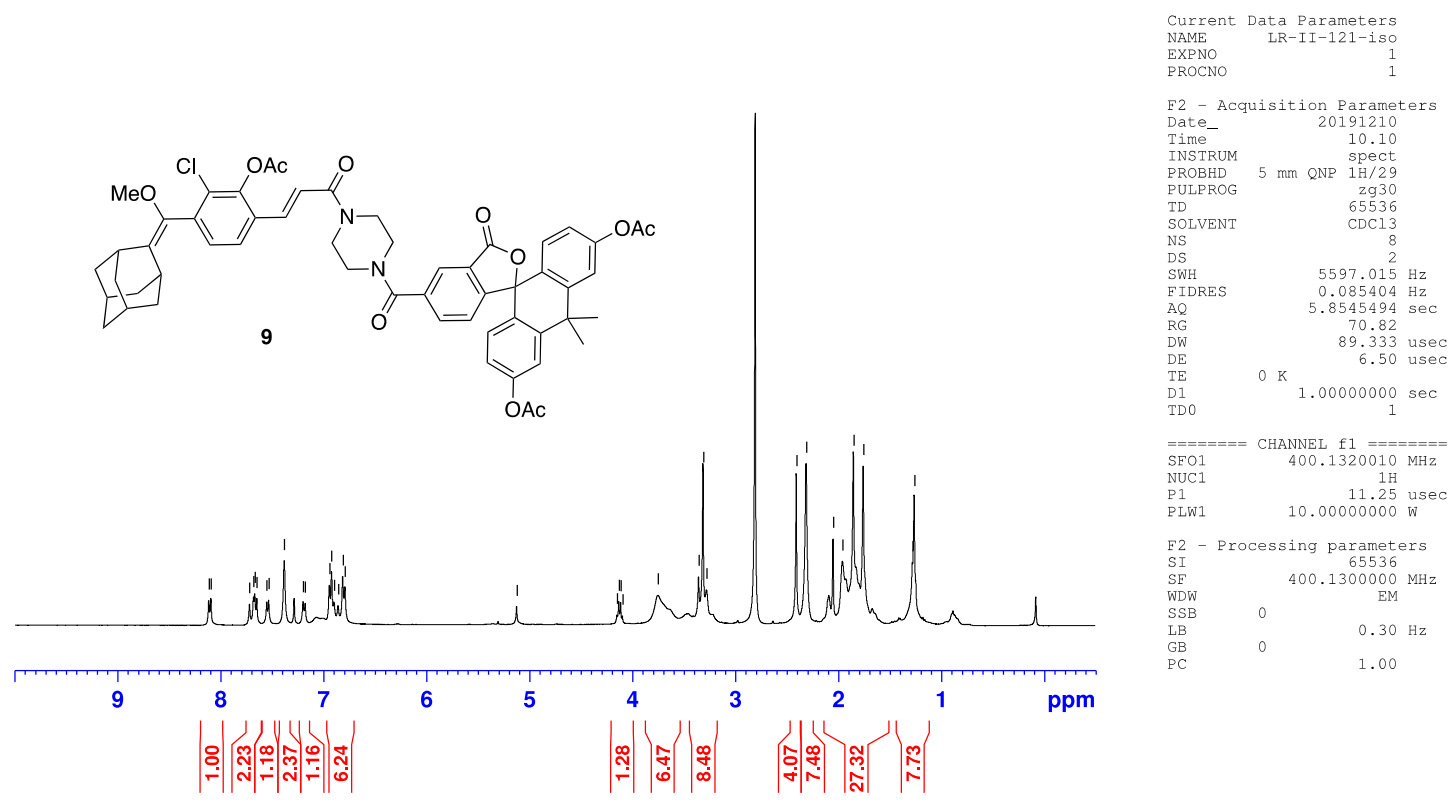

Figure S15. ${ }^{1} \mathrm{H}$ NMR spectrum $\left(400 \mathrm{MHz}, \mathrm{CDCL}_{3}\right)$ of 9. 

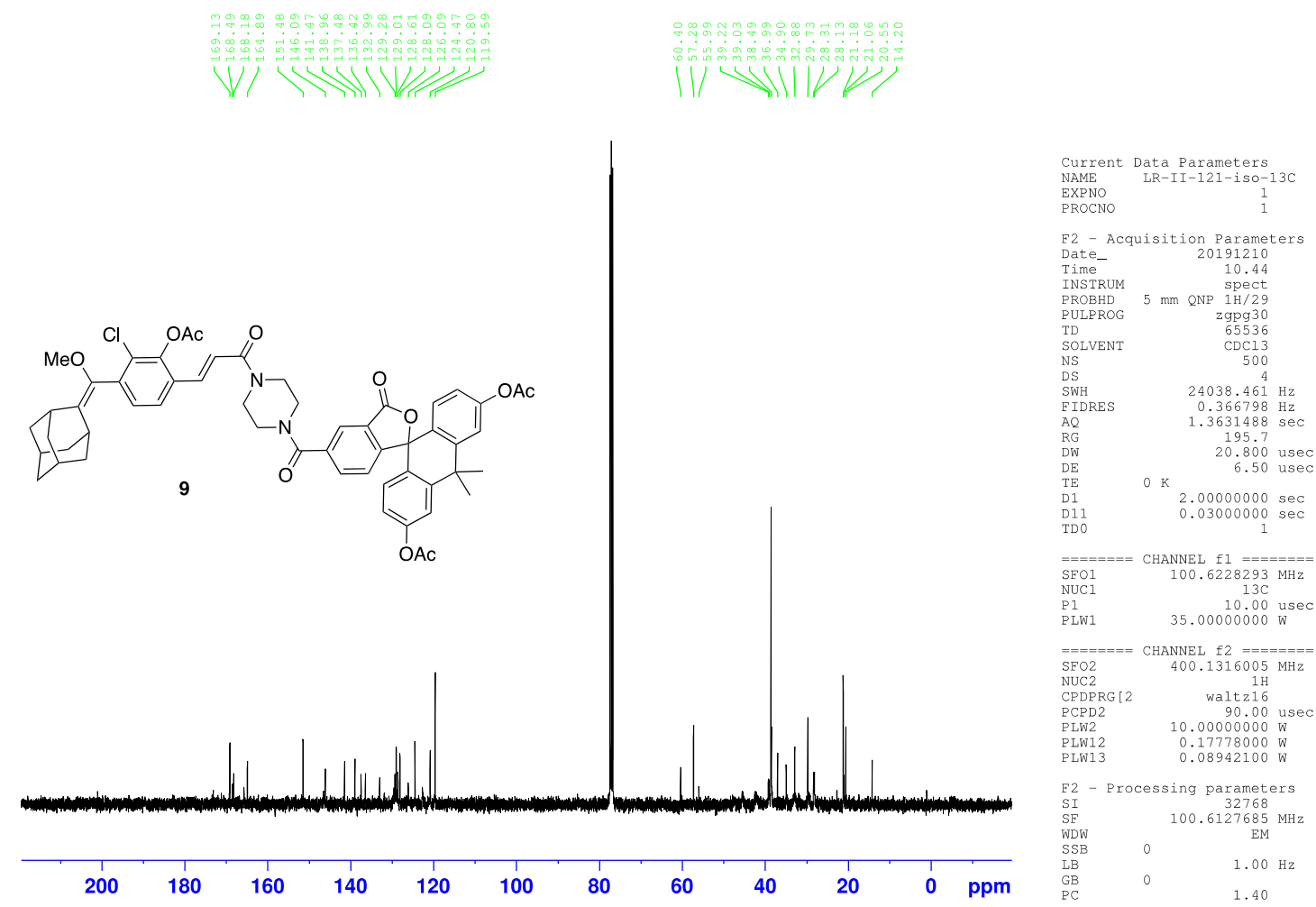

Figure S16. ${ }^{13} \mathrm{C}$ NMR $\left(100 \mathrm{MHz}, \mathrm{CDCl}_{3}\right)$ of 9. 

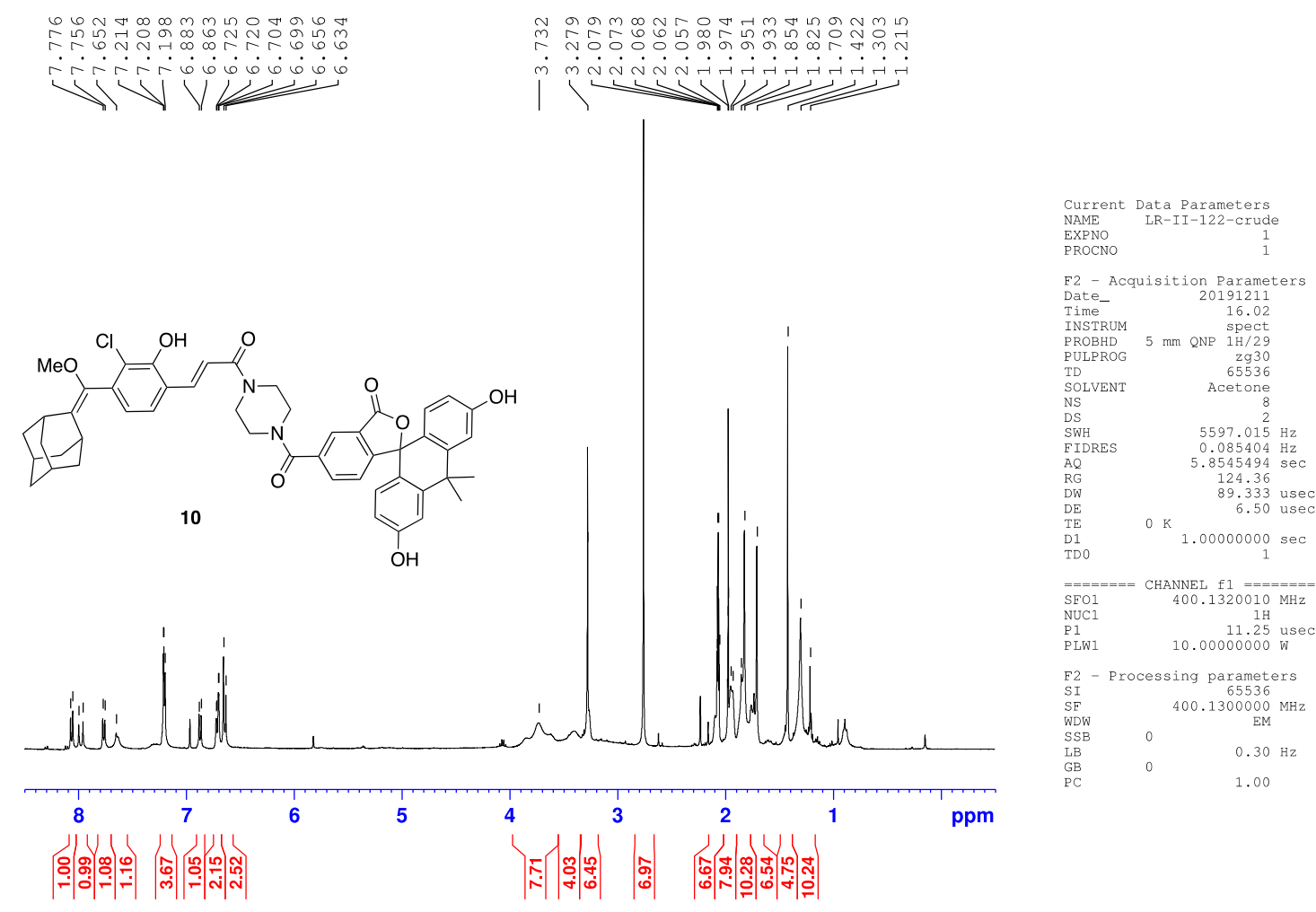

Figure S17. ${ }^{1} \mathrm{H}$ NMR spectrum (400 MHz, Acetone-D6) of 10. 


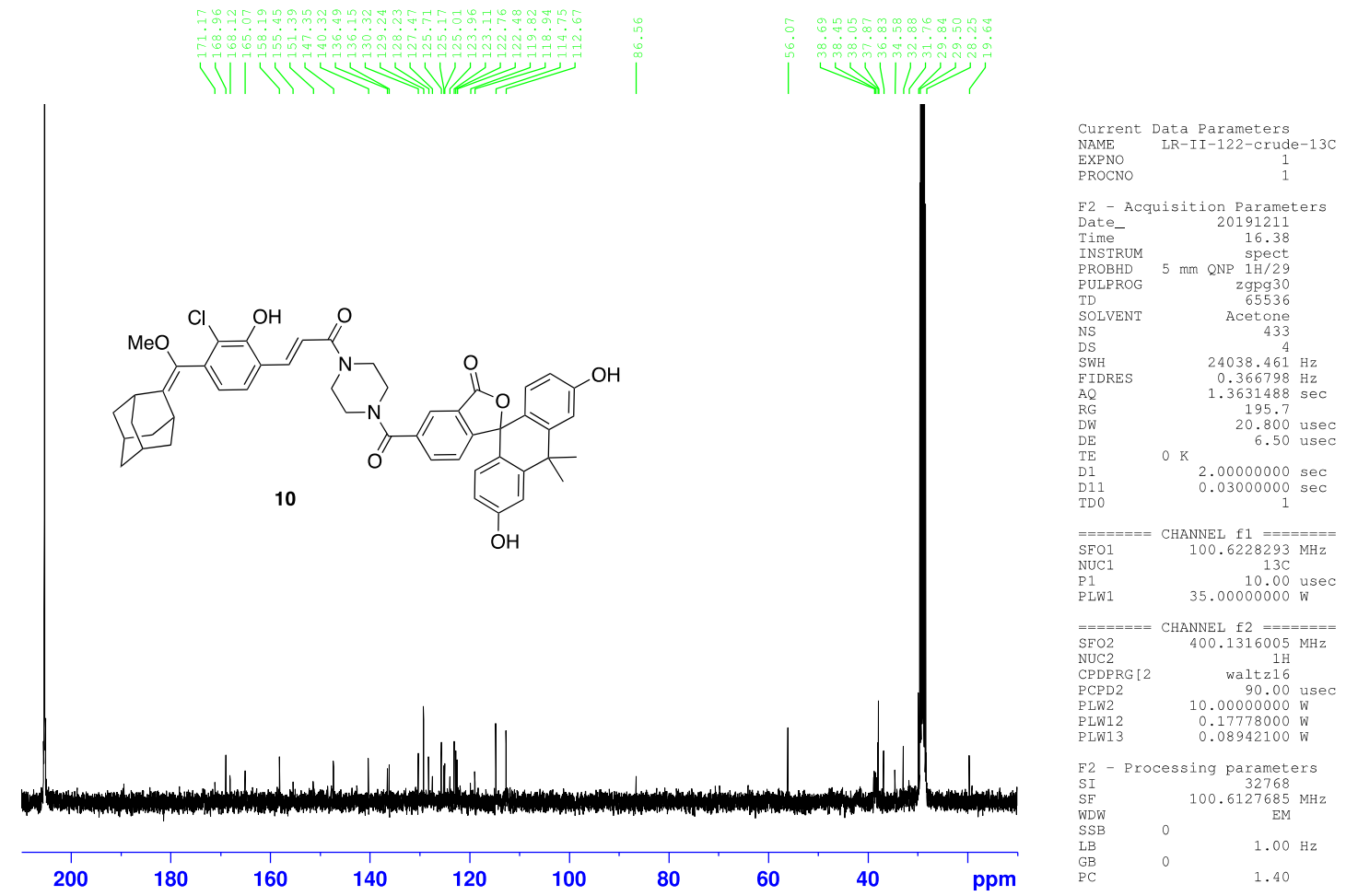

Figure S18. ${ }^{13} \mathrm{C}$ NMR spectrum $(100 \mathrm{MHz}$, Acetone-D6) of $\mathbf{1 0}$. 

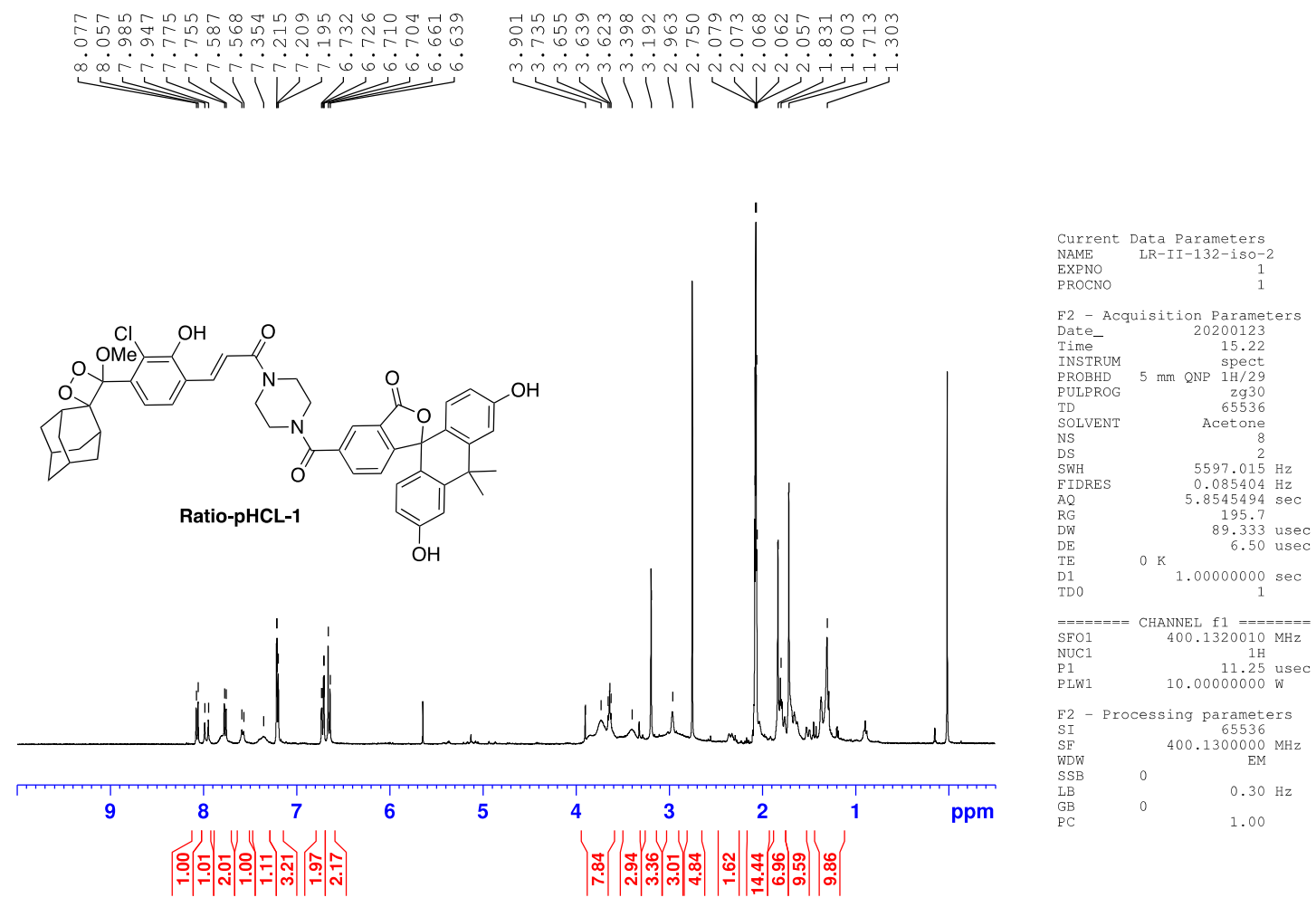

Figure S19. ${ }^{1} \mathrm{H}$ NMR spectrum (400 MHz, Acetone-D6) of Ratio-pHCL-1. 

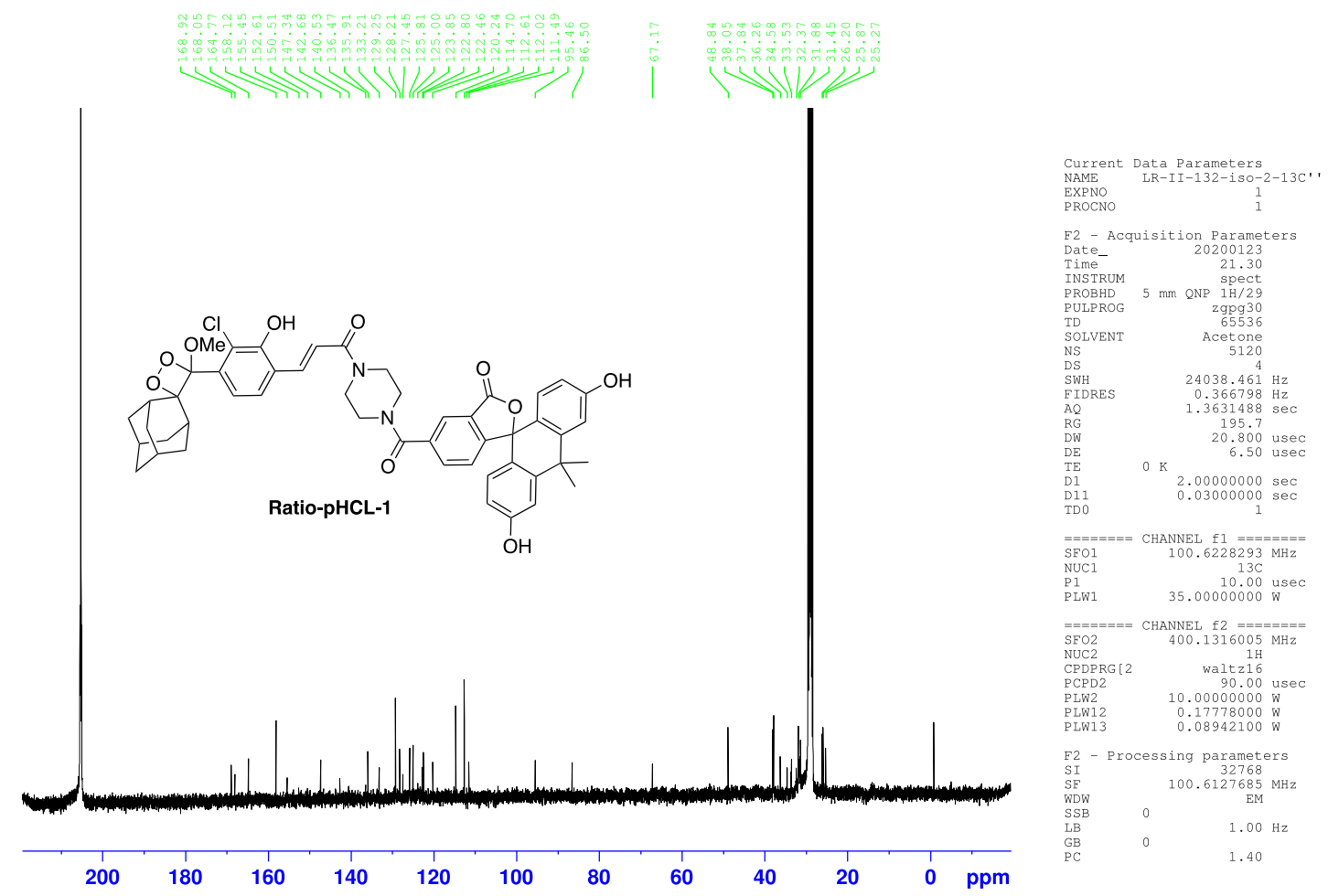

Figure S20. ${ }^{13} \mathrm{C}$ NMR spectrum of Ratio-pHCL-1. 
